\title{
Novel Amphiphilic Block Copolymers for the Formation of Stimuli-Responsive Non-Lamellar Lipid Nanoparticles
}

\author{
Jiali Zhai ${ }^{1, *(\mathbb{D})}$, Bo Fan ${ }^{2} \mathbb{D}$, San H. Thang ${ }^{2} \mathbb{D}$ and Calum J. Drummond ${ }^{1, *(D)}$ \\ 1 School of Science, STEM College, RMIT University, Melbourne, VIC 3000, Australia \\ 2 School of Chemistry, Monash University, Clayton, VIC 3800, Australia; bo.fan@monash.edu (B.F.); \\ san.thang@monash.edu (S.H.T.) \\ * Correspondence: maggie.zhai@rmit.edu.au (J.Z.); calum.drummond@rmit.edu.au (C.J.D.)
}

check for updates

Citation: Zhai, J.; Fan, B.; Thang, S.H.; Drummond, C.J. Novel Amphiphilic Block Copolymers for the Formation of Stimuli-Responsive Non-Lamellar Lipid Nanoparticles. Molecules 2021, 26, 3648. https:// doi.org/10.3390/molecules 26123648

Academic Editor: Mathieu Berchel

Received: 26 May 2021

Accepted: 10 June 2021

Published: 15 June 2021

Publisher's Note: MDPI stays neutral with regard to jurisdictional claims in published maps and institutional affiliations.

Copyright: (c) 2021 by the authors. Licensee MDPI, Basel, Switzerland. This article is an open access article distributed under the terms and conditions of the Creative Commons Attribution (CC BY) license (https:// creativecommons.org/licenses/by/ $4.0 /)$.
Abstract: Non-lamellar lyotropic liquid crystalline (LLC) lipid nanoparticles contain internal multidimensional nanostructures such as the inverse bicontinuous cubic and the inverse hexagonal mesophases, which can respond to external stimuli and have the potential of controlling drug release. To date, the internal LLC mesophase responsiveness of these lipid nanoparticles is largely achieved by adding ionizable small molecules to the parent lipid such as monoolein (MO), the mixture of which is then dispersed into nanoparticle suspensions by commercially available poly(ethylene oxide)poly(propylene oxide) block copolymers. In this study, the Reversible Addition-Fragmentation chain Transfer (RAFT) technique was used to synthesize a series of novel amphiphilic block copolymers (ABCs) containing a hydrophilic poly(ethylene glycol) (PEG) block, a hydrophobic block and one or two responsive blocks, i.e., poly(4-(4,4,5,5-tetramethyl-1,3,2-dioxaborolan-2-yl)benzyl acrylate) (PTBA) and/or poly(2-(dimethylamino)ethyl methacrylate) (PDMAEMA). High throughput small angle X-ray scattering studies demonstrated that the synthesized ABCs could simultaneously stabilize a range of LLC MO nanoparticles (vesicles, cubosomes, hexosomes, inverse micelles) and provide internal particle nanostructure responsiveness to changes of hydrogen peroxide $\left(\mathrm{H}_{2} \mathrm{O}_{2}\right)$ concentrations, $\mathrm{pH}$ and temperature. It was found that the novel functional ABCs can substitute for the commercial polymer stabilizer and the ionizable additive in the formation of next generation non-lamellar lipid nanoparticles. These novel formulations have the potential to control drug release in the tumor microenvironment with endogenous $\mathrm{H}_{2} \mathrm{O}_{2}$ and acidic $\mathrm{pH}$ conditions.

Keywords: monoolein; cubosome; RAFT; PDMAEMA; responsive nanoparticles; drug delivery; lyotropic liquid crystals; amphiphile block copolymer

\section{Introduction}

Lipid-based cubosomes and hexosomes are a class of lipid nanoparticles containing the intriguing non-lamellar lyotropic liquid crystalline (LLC) mesophases, i.e., the inverse bicontinuous cubic $\left(\mathrm{Q}_{\mathrm{II}}\right)$ phase and the inverse hexagonal $\left(\mathrm{H}_{\mathrm{II}}\right)$ phase, respectively, which are formed by amphiphilic lipid self-assembly in aqueous conditions (Figure 1) [1-6]. Over the past three decades, the unique multidimensional and porous structural characteristics [7-9] of the non-lamellar LLC mesophases within cubosomes and hexosomes have driven a considerable amount of interest in a range of biomedical applications, including drug delivery [10-17] theranostic application [18] and imaging [19-22]. The QII phase inside cubosomes can be described as a continuous, tortuous lipid bilayer draped over an infinite periodic minimal surface and composed of two interpenetrating water channels, possessing a large interfacial area [23]. The $\mathrm{H}_{\mathrm{II}}$ phase inside hexosomes is characterized by elongated water tubes lined by lipid layers and packed in a hexagonal array [24]. A large body of literature has demonstrated the advantages of non-lamellar LLC lipid nanoparticles as drug delivery systems, including the versatility of encapsulating hydrophilic and hydrophobic drugs with high encapsulation efficiency [25], ability to protect and deliver large 
biomolecules (proteins, peptides, DNAs) [15,26-29] and tunability and responsiveness to external stimuli for controlling drug release [30-33]. Furthermore, improved efficacy of the encapsulated drugs within cubosomes and hexosomes has been frequently demonstrated in in vivo preclinical models [34-37].

\section{A. Monoolein and CPP model}

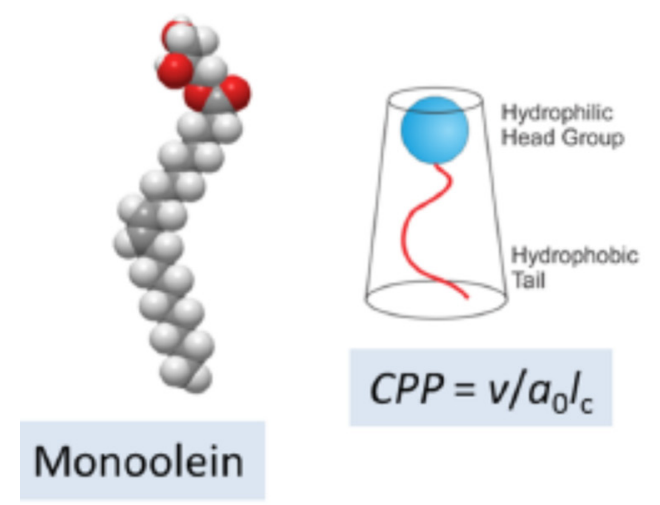

B. Common LLC mesophases of amphiphilic lipid self-assemblies

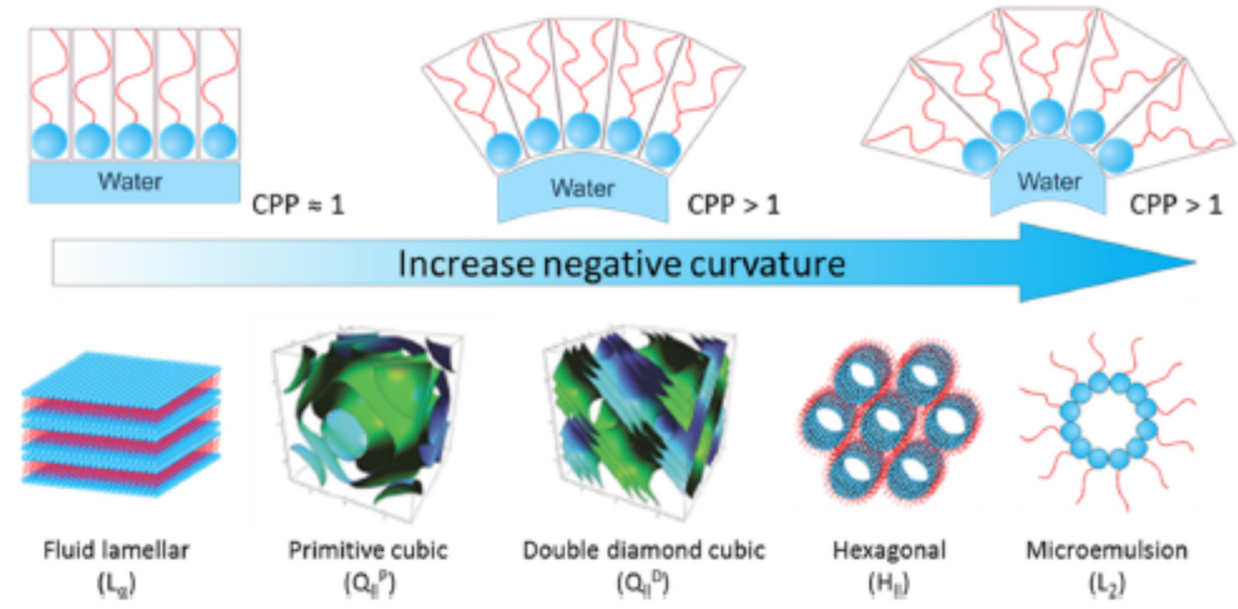

Figure 1. (A) Monoolein (MO) molecular model and critical packing parameter (CPP) representation, where $v$ is the hydrophobic chain volume, $a_{0}$ is the effective headgroup area and $l_{c}$ is the effective hydrophobic chain length. (B) Structures of commonly observed self-assembled lyotropic liquid crystalline (LLC) mesophases of amphiphilic lipids such as MO, presented in the order of increasing negative lipid membrane curvature. Reproduced from Zhai et al. [6]. Copyright 2019, American Chemical Society.

Responsiveness to external stimuli is often a desirable attribute of nanoparticle drug delivery systems as the goal is to deliver the drug at specific target sites at a controlled rate. In this regard, the tunability of non-lamellar LLC mesophases, i.e., the phase transition between the lamellar $(\mathrm{L} \alpha), \mathrm{Q}_{\mathrm{II}}, \mathrm{H}_{\mathrm{II}}$ and the inverse micellar $\left(\mathrm{L}_{2}\right)$ phase within the nanoparticles, in response to environmental factors such as temperature and $\mathrm{pH}$, has become an active research area $[22,30,31,33,38-41]$. Different internal mesophases within nanoparticles can influence drug encapsulation efficiency and release rate $[6,25,42]$, cytotoxicity profile [43] and in vivo biodistribution and efficacy [19]. For example, the responsiveness of the internal mesophase to $\mathrm{pH}$ has been achieved by the addition of $\mathrm{pH}$-sensitive amphiphilic molecule such as a long-chain fatty acid or an ionizable lipid to the parent lipid system [30,44-47]. The mechanism of the $\mathrm{pH}$-induced phase transition can be rationalized by the critical packing parameter $(\mathrm{CPP})$ concept $\left(\mathrm{CPP}=v / a_{0} l_{c}\right)$, where $v$ is the volume of the hydrocarbon chain, $a_{0}$ is the effective headgroup area and $l_{c}$ is the maximum length of the 
hydrocarbon chain (Figure 1) [48]. Our recent study demonstrated $\mathrm{pH}$ responsiveness of the internal mesophase of $\mathrm{MO}$ nanoparticles enriched by synthetic ionizable aminolipids with the amino headgroup possessing a $\mathrm{pK}_{\mathrm{a}}$ around $\mathrm{pH} 7$ [47]. The ionization state of the aminolipid population can be manipulated by varying the $\mathrm{pH}$ level above or below the apparent $\mathrm{pK}_{\mathrm{a}}$ of the ionizable moiety at the lipid-water interface. Under acidic $\mathrm{pH}$ conditions, the aminolipid headgroup becomes positively charged and electrostatic repulsion between the headgroups can significantly enlarge the effective headgroup area, reducing the CPP value and causing a phase transition to a mesophase with lower negative interfacial curvature. Specifically, MO nanoparticles enriched by the aminolipids underwent a phase transition from the $\mathrm{H}_{\text {II }}$ to the $\mathrm{Q}_{\text {II }}$ mesophase as the $\mathrm{pH}$ was reduced [47].

Most of the current cubosome formulations utilize commercially available poly(ethylene oxide)-poly(propylene oxide) block copolymer (e.g., Pluronic F127 or F108), which do not have intrinsic responsiveness to physiologically relevant stimuli such as $\mathrm{pH}$ and temperature. As discussed above, responsiveness can be achieved by adding additional amphiphilic molecules; however, such formulations still require the presence of steric stabilizers to produce stable nanoparticulate dispersions. There have been a number of studies on alternative polymers to substitute for Pluronic polymers for preparing LLC lipid nanoparticles, and a range of synthetic and commercially available polymers [49], including amphiphilic brush copolymers [50,51], poly(ethylene glycol) (PEG)-conjugated lipids [51-53] and amphiphilic proteins [54], have been explored. Numerous studies have shown that the choice of steric stabilizer not only can influence the particle size, size distribution and the internal mesophase of the formed lipid nanoparticles [49,55], but can have benefits of reducing cytotoxicity profile [56,57] and manipulating complement response [52].

However, there has been very limited studies using responsive polymers to make nonlamellar lipid nanoparticles which exhibit phase transitions in response to environmental conditions. Recently, Chountoulesi et al. synthesized a stimuli-responsive polycationic block copolymer, poly(2-(dimethylamino)ethyl methacrylate)-b-poly(lauryl methacrylate) (PDMAEMA-b-PLMA), to stabilize for MO nanoparticles and indicated that the nanoparticles responded to $\mathrm{pH}$ and temperature changes [58]. However, the study did not directly identify the internal LLC mesophase but used the fractal dimension parameter as an indicator to suggest mesophase or morphological change. Another recent study by Jenni et al. conjugated the diketopyrrolopyrrole-porphyrin based photosensitizer to Pluronic F108 and used the conjugate to stabilize cubosomes [16]. Docetaxel as a model drug was loaded into the cubosomes stabilized by the photosensitizer-polymer conjugate and the drug release and efficacy was demonstrated to be enhanced following irradiation.

Herein, we report the Reversible Addition-Fragmentation chain Transfer (RAFT) synthesis of a class of novel amphiphilic block copolymers (ABCs) which are dually functional. These ABCs not only act as a stabilizing agent for non-lamellar lipid nanoparticulate dispersions but also possess responsive chemical groups to impart an ability for LLC mesophase transition to occur with changes to physiologically and pathologically relevant $\mathrm{pH}$, temperature and hydrogen peroxide $\left(\mathrm{H}_{2} \mathrm{O}_{2}\right)$ conditions, such as in the gastrointestinal tract or in a tumor microenvironment (TME). The synthetic $\mathrm{ABC}$ s were designed with a hydrophobic segment to promote partitioning into the MO lipid layer, an extended hydrophilic PEG segment for steric stabilization, and responsive functional moieties (chemical structures given in Figure 2). The functional moiety of pinacol boronic ester in poly (4-(4,4,5,5-tetramethyl1,3,2-dioxaborolan-2-yl)benzyl acrylate) (PTBA) is responsive to $\mathrm{H}_{2} \mathrm{O}_{2}$ [59], while the PDMAEMA is a dually responsive polymer in response to a change of $\mathrm{pH}$ and temperature [60]. MO was chosen because it is the most studied and well-characterized lipid in the formulation of non-lamellar lipid nanoparticles [6,61]. We utilized high-throughput formulation methodology to prepare $\mathrm{MO}$ nanoparticles stabilized by the synthetic $\mathrm{ABC}$ at six different concentrations [62]. Direct identification of the LLC mesophase within the nanoparticles was undertaken by utilizing synchrotron small angle X-ray scattering (SAXS), and the effect of the $\mathrm{ABC}$ structure, concentration and three environmental factors ( $\mathrm{pH}$, temperature and $\mathrm{H}_{2} \mathrm{O}_{2}$ ) on the internal LLC mesophase of the formed particles was 
systematically investigated. This study reports the synthesis of novel, dually functional ABCs which can successfully stabilize MO nanoparticles and provide mesophase responsiveness to environmental factors; thereby further advancing the field of stimuli-responsive non-lamellar LLC lipid nanoparticles as prospective drug carriers.

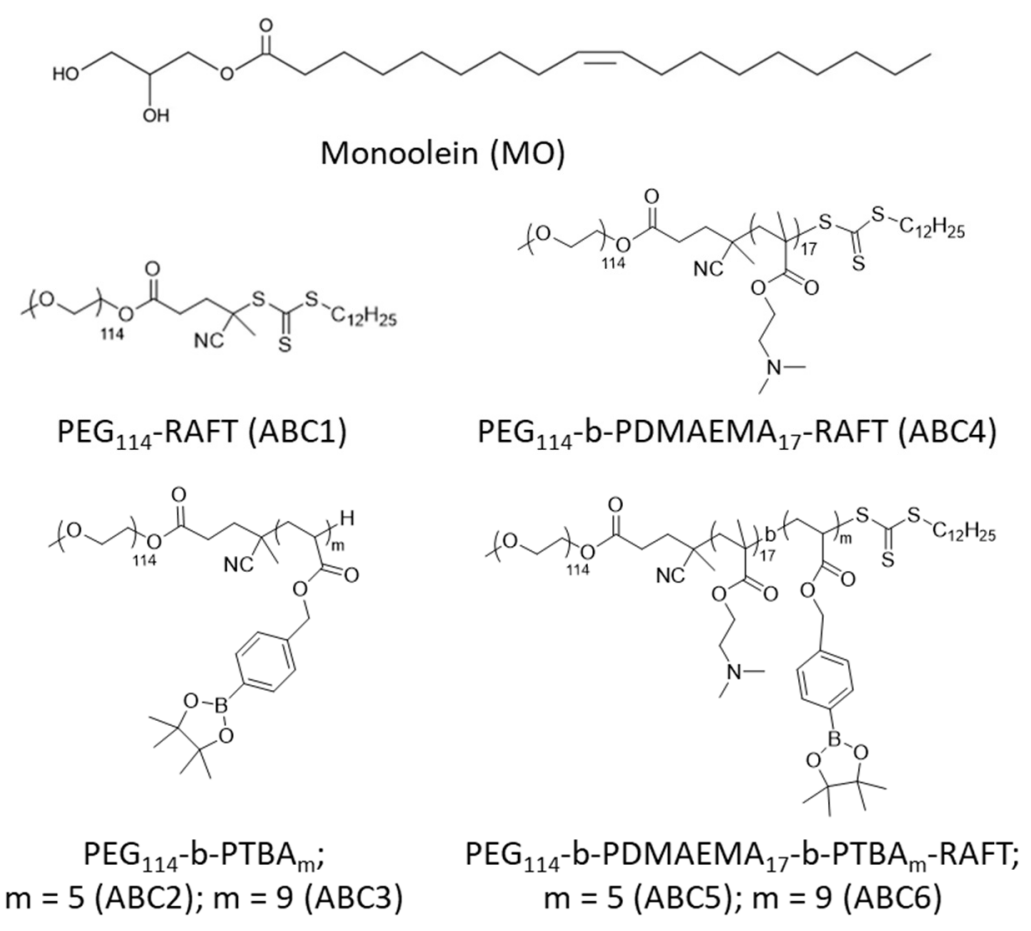

Figure 2. Chemical structures of MO and the synthetic ABCs used in the study.

\section{Results}

\subsection{Synthesis of Stimuli-Responsive ABCs}

To synthesize the stimuli-responsive ABCs, PEG methyl ether ( $\mathrm{PEG}_{114}$, average $M_{\mathrm{n}}=5000 \mathrm{~g} / \mathrm{mol}$ ) was firstly coupled with RAFT agent 4-cyano-4 (((dodecylthio) carbonothioyl)thio) pentanoic acid (CDPA) through Steglich esterification. CDPA is a commercially available RAFT agent that was widely used to control the polymerization of different types of monomers, including styrene, (meth)acrylate and (meth)acrylamide [63-66]. The long alkyl chain of CDPA allows it to work as the hydrophobic tail in ABC1. Next, ABC1 was chain extended with monomers (TBA and DMAEMA) at different ratios to afford ABC2-ABC6. Notably, the RAFT end-groups in $\mathrm{ABC} 2$ and $\mathrm{ABC} 3$ were removed via radical-induced reduction to compare the effect of different hydrophobic blocks on the formation of LLC mesophases. These polymers are well-controlled and exhibit low dispersities $(\Theta=1.08-1.17)$. The detailed synthesis procedures are provided in the experimental section. The ${ }^{1} \mathrm{H}$ nuclear magnetic resonance (NMR) spectra and gel permeation chromatography (GPC) curves are listed in Supplementary Information Figures S1-S12.

\subsection{Formulation and Characterization of $M O$ Nanoparticles Stabilized by the Synthetic ABCs}

To assess the ability of the synthetic ABCs to make LLC mesophase-containing MO nanoparticles, the polymers were added at a concentration range of $0.5-3.0 \mathrm{~mol} \%$ to a fixed amount of $\mathrm{MO}(20 \mathrm{mg} / \mathrm{mL})$, followed by high power sonication. Initial visual examination showed that almost all six ABCs could disperse the lipid into milky nanoparticle solutions without visible lipid aggregates, but the samples became more translucent as the polymer concentration increased (Supplementary Information Table S1). The $\mathrm{PEG}_{114}-b-\mathrm{PTBA}_{5}$ polymer (ABC2) could not disperse the lipid at the lowest concentration $(0.5 \mathrm{~mol} \%)$ into a homogenous solution with a population of small lipid aggregates observed in the sample. The particle size and the size distribution of the formed nanoparticles were examined 
within $24 \mathrm{~h}$ of formulation, and results are given in Supplementary Information Table S2. The results were consistent with the morphological observation. The sample stabilized by $0.5 \mathrm{~mol} \%$ ABC2 had the largest average particle size $(301 \mathrm{~nm})$ and was the most polydisperse (polydispersity index $(\mathrm{PDI})=0.38$ ). The particle size of the majority of the MO nanoparticles was in the range of $140-300 \mathrm{~nm}$ and the PDI was in the range of $0.1-0.3$, both within the expected range compared to previous studies of a wide range of LLC lipid nanoparticles $[47,67]$.

The internal LLC mesophase of the formed nanoparticles was examined by highthroughput synchrotron SAXS and the one-dimensional SAXS profile of each formulation is given in Figure 3. The assigned LLC mesophase and the calculated lattice parameter (a) for each formulation is summarized in Table 1. Note that mesophase assignment of representative samples using the characteristic peak spacing ratio for each mesophase is given in Supplementary Figure S13. The results show that the internal mesophase of the formed nanoparticle depends on the polymer structure as well as the added polymer concentration. MO nanoparticles stabilized by $0.5 \mathrm{~mol}^{\%} \mathrm{PEG}_{114}$-RAFT (ABC1) with a hydrophobic $\mathrm{C} 12$ end and a hydrophilic $\mathrm{PEG}_{114}$ block lost the internal $\mathrm{Q}_{\text {II }}$ phase to a large extent, which was then lost completely at higher polymer concentrations, indicating strong partitioning of the $\mathrm{ABC} 1$ polymer into the lipid layer and disruption of the parent $\mathrm{MO}$ cubic membrane packing.

Polymers $\mathrm{ABC} 2$ and $\mathrm{ABC} 3$ do not possess the $\mathrm{C} 12 \mathrm{RAFT}$ end-group and instead have 5 and 9 repeating units of TBA groups, respectively. $\mathrm{ABC} 2$-stabilized $\mathrm{MO}$ nanoparticles contained the primitive $\mathrm{Q}_{\text {II }}\left(\mathrm{Q}_{\text {II }}{ }^{\mathrm{P}}\right)$ phase with symmetry group $\operatorname{Im} 3 m$ up to $1.5 \mathrm{~mol} \%$ and in comparison, nanoparticles stabilized by $\mathrm{ABC} 3$ retained the $\mathrm{Q}_{\mathrm{II}}{ }^{\mathrm{P}}$ phase even at the highest concentration $(3 \mathrm{~mol} \%)$. Examination of the lattice parameters $(a)$ revealed an interesting trend that increasing the concentration of polymer $A B C 2$ and $A B C 3$ had a swelling effect on the $\mathrm{Q}_{\mathrm{II}}^{\mathrm{P}}$ phase with the $a$ of $3.0 \mathrm{~mol} \%$ ABC3-stabilized cubosome having the largest value of $178 \AA$. The increase in $a$ indicates swelling of the internal water channels within the mesophase. However, it should be noted that the diffraction signals of the highly swollen $\mathrm{Q}_{\mathrm{II}}^{\mathrm{P}}$ phase were relatively weak. Overall, the results indicate that polymers $\mathrm{ABC1}$, $\mathrm{ABC} 2$ and $\mathrm{ABC} 3$ can be incorporated into the $\mathrm{MO}$ lipid membrane and reduce the negative membrane curvature to various degrees; such effect is in the order of $\mathrm{ABC} 1>\mathrm{ABC} 2>$ $\mathrm{ABC} 3$ and increases with the concentration of the polymer within the system.
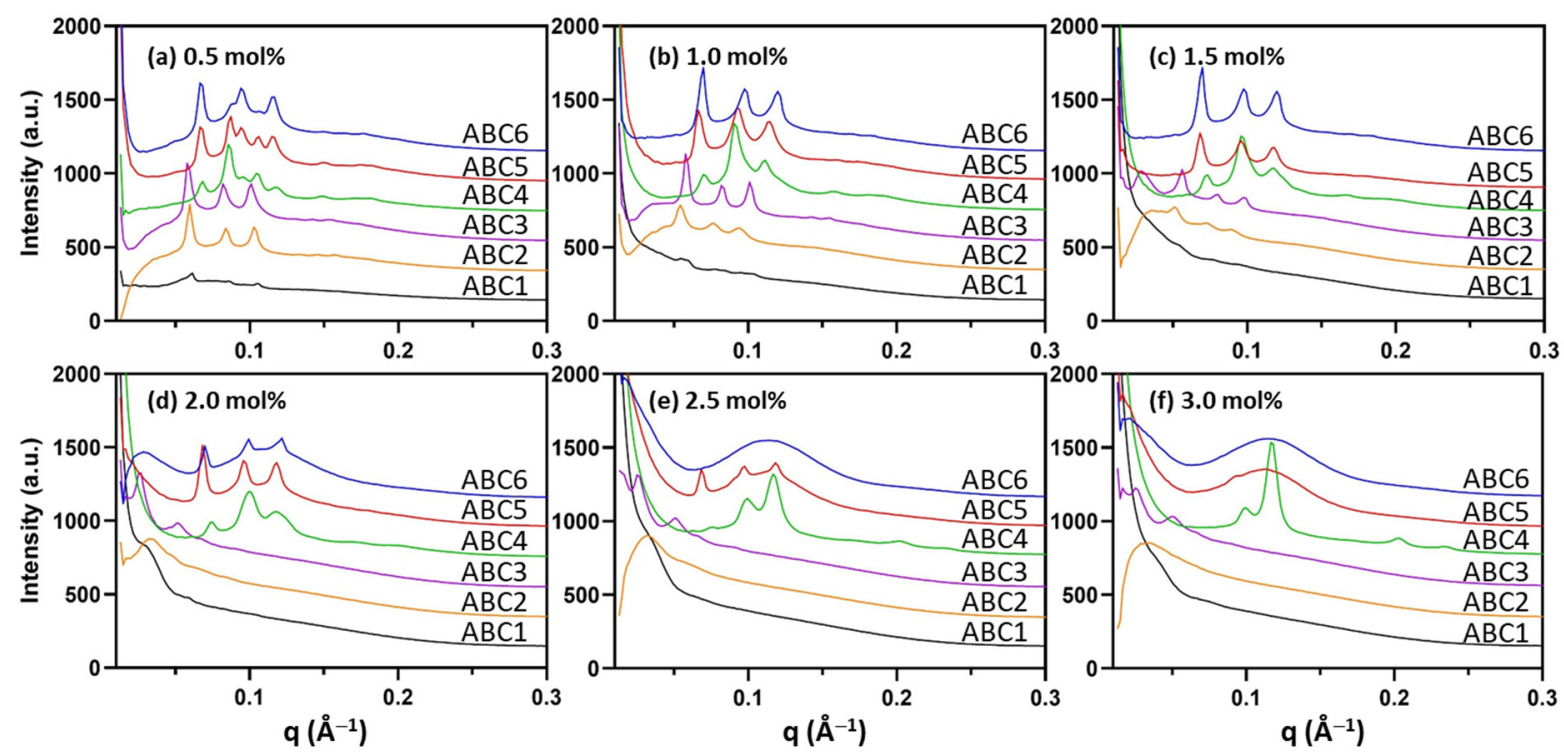

Figure 3. SAXS diffraction patterns of MO nanoparticles stabilized by the synthetic ABCs at (a) $0.5 \mathrm{~mol} \%$; (b) $1.0 \mathrm{~mol} \%$; (c) $1.5 \mathrm{~mol} \%$; (d) $2.0 \mathrm{~mol} \%$; (e) $2.5 \mathrm{~mol} \%$; (f) $3.0 \mathrm{~mol} \%$ to the amount of MO. All measurements were performed at $25{ }^{\circ} \mathrm{C}$. 
Table 1. Mesophase identification and calculated lattice parameters ( $\mathrm{A})$ of the MO nanoparticles stabilized by the synthetic ABCs.

\begin{tabular}{|c|c|c|c|c|c|c|}
\hline $\mathrm{mol} \%$ & $\mathrm{ABC1}$ & $\mathrm{ABC2}$ & $\mathrm{ABC} 3$ & ABC4 & ABC5 & ABC6 \\
\hline 0.5 & $\begin{array}{l}\text { Weak } \operatorname{Im} 3 m \\
\text { signal }\end{array}$ & $\operatorname{Im} 3 \mathrm{~m}(145)$ & $\operatorname{Im} 3 \mathrm{~m}(153)$ & $\begin{array}{c}\text { Pn3m } \\
(101) ; \\
\operatorname{Im} 3 m(127)\end{array}$ & $\begin{array}{l}\text { Im3m (131); } \\
\text { Pn3m (103) }\end{array}$ & $\begin{array}{l}\text { Im3m (130) } \\
\text { Pn3m (103) }\end{array}$ \\
\hline 1.0 & $\begin{array}{c}\text { Weak } \operatorname{Im} 3 \mathrm{~m} \\
\text { signal }\end{array}$ & $\operatorname{Im} 3 \mathrm{~m}(162)$ & $\operatorname{Im} 3 m(153)$ & $\begin{array}{l}\text { Pn3m (98); } \\
\text { Im3m (115) }\end{array}$ & $\operatorname{Im} 3 m(132)$ & $\operatorname{Im} 3 \mathrm{~m}(126)$ \\
\hline 1.5 & ND & $\operatorname{Im} 3 \mathrm{~m}(174)$ & $\operatorname{Im} 3 \mathrm{~m}(157)$ & $\begin{array}{l}\text { Pn3m (92); } \\
\text { Im3m (112) }\end{array}$ & $\operatorname{Im} 3 m(130)$ & $\operatorname{Im} 3 \mathrm{~m}(126)$ \\
\hline 2.0 & ND & ND & $\operatorname{Im} 3 \mathrm{~m}(176)$ & $\begin{array}{l}\text { Pn3m (89); } \\
\text { Im3m (112) }\end{array}$ & $\operatorname{Im} 3 m(129)$ & $\operatorname{Im} 3 m(125)$ \\
\hline 2.5 & ND & ND & $\operatorname{Im} 3 \mathrm{~m}(176)$ & $\begin{array}{c}\mathrm{Pn} 3 \mathrm{~m}(90) \\
\mathrm{H}_{2}(61)\end{array}$ & $\begin{array}{c}\operatorname{Im} 3 m(130) \\
L_{2}\end{array}$ & $\mathrm{~L}_{2}$ \\
\hline 3.0 & ND & ND & $\operatorname{Im} 3 \mathrm{~m}(178)$ & $\begin{array}{c}\mathrm{Pn} 3 \mathrm{~m}(90) \\
\mathrm{H}_{2}(62)\end{array}$ & $\mathrm{L}_{2}$ & $\mathrm{~L}_{2}$ \\
\hline
\end{tabular}

Note: $\operatorname{Im} 3 m$ refers to the primitive $\mathrm{Q}_{\mathrm{II}}\left(\mathrm{Q}_{\mathrm{II}}{ }^{\mathrm{P}}\right)$ phase with the symmetry group $\mathrm{Im} 3 m$; Pn3m refers to the doublediamond $\mathrm{Q}_{\mathrm{II}}\left(\mathrm{Q}_{\mathrm{II}}{ }^{\mathrm{D}}\right)$ phase with the symmetry group $P n 3 m ; \mathrm{H}_{\mathrm{II}}$ refers to the inverse hexagonal phase: $\mathrm{L}_{2}$ refers to the inverse micellar phase; ND refers to no distinctive diffraction pattern identified.

Interestingly, the PDMAEMA-containing polymers (ABC4, $\mathrm{ABC} 5, \mathrm{ABC6})$ had the opposite effect of increasing the negative membrane curvature. In the case of the $\mathrm{PEG}_{114}-b$ PDMAEMA $_{17}$-RAFT polymer (ABC4), the MO nanoparticle stabilized by $0.5 \mathrm{~mol} \% \mathrm{ABC} 4$ contained mixed mesophases of the $\mathrm{Q}_{\text {II }}{ }^{\mathrm{P}}$ phase and the double diamond $\mathrm{Q}_{\text {II }}\left(\mathrm{Q}_{\text {II }}{ }^{\mathrm{D}}\right)$ phase with $a$ of $127 \AA$ and $101 \AA$, respectively. As the polymer concentration increased, the $a$ values for each phase gradually decreased and at the highest concentrations $(2.5 \mathrm{~mol} \%$ and $3 \mathrm{~mol} \%$ ), the internal mesophase transformed to co-existing $\mathrm{Q}_{\text {II }} \mathrm{D}$ and $\mathrm{H}_{\text {II }}$ phases, further confirming the increase in the negative membrane curvature. The sub-set of $\mathrm{PEG}_{114}-b$ PDMAEMA $_{17}-b-$ PTBA $_{\mathrm{m}}$-RAFT polymers (ABC5 and ABC6) both acted similarly with a mesophase transition from the $\mathrm{Q}_{\text {II }}{ }^{\mathrm{P}}$ phase to the $\mathrm{L}_{2}$ phase as the polymer concentration increased. At the lowest concentration $(0.5 \mathrm{~mol} \%)$, both $\mathrm{ABC} 5$ - and ABC6-stabilized MO nanoparticles exhibited mixed $\mathrm{Q}_{\text {II }}{ }^{\mathrm{P}}(a=131 \AA)$ and $\mathrm{Q}_{\text {II }}{ }^{\mathrm{D}}(a=103 \AA)$ phases. The mesophase transition concentration, however, differed for the two $\mathrm{ABC}$ s with $\mathrm{ABC} 6$ causing a complete transition to the $\mathrm{L}_{2}$ phase at $2.5 \mathrm{~mol} \%$ and $\mathrm{ABC} 5$ at $3.0 \mathrm{~mol} \%$. These results also indicate that the negative curvature promoting effect is in the order of $\mathrm{ABC} 6>\mathrm{ABC} 5>\mathrm{ABC} 4$ and increases with the concentration of the polymer.

\section{3. $\mathrm{H}_{2} \mathrm{O}_{2}$-Responsiveness of the Formulated Nanoparticles}

The hydrophobicity of the PTBA-containing polymers is expected to decrease in a $\mathrm{H}_{2} \mathrm{O}_{2}$ environment due to $\mathrm{H}_{2} \mathrm{O}_{2}$-induced degradation of the pinacol boronic ester group followed by the loss of the aromatic ring [59]. Therefore, $\mathrm{MO}$ nanoparticles stabilized by PTBA-containing polymers may undergo LLC mesophase changes in the presence of $\mathrm{H}_{2} \mathrm{O}_{2}$, as the polymer side-group structure changes. To assess the mesophase responsiveness of the formulated nanoparticles stabilized by PTBA block-containing polymers, $50 \mathrm{mM}$ $\mathrm{H}_{2} \mathrm{O}_{2}$ was added to the nanoparticulate dispersions stabilized by $\mathrm{ABC} 3, \mathrm{ABC} 5$ and $\mathrm{ABC} 6$ and the SAXS results are given in Figure 4 and Table 2. Polymer ABC4 with no PTBA block served as a control and results confirm no LLC mesophase changes in $50 \mathrm{mM} \mathrm{H}_{2} \mathrm{O}_{2}$ (Supplementary Information Figure S14). 

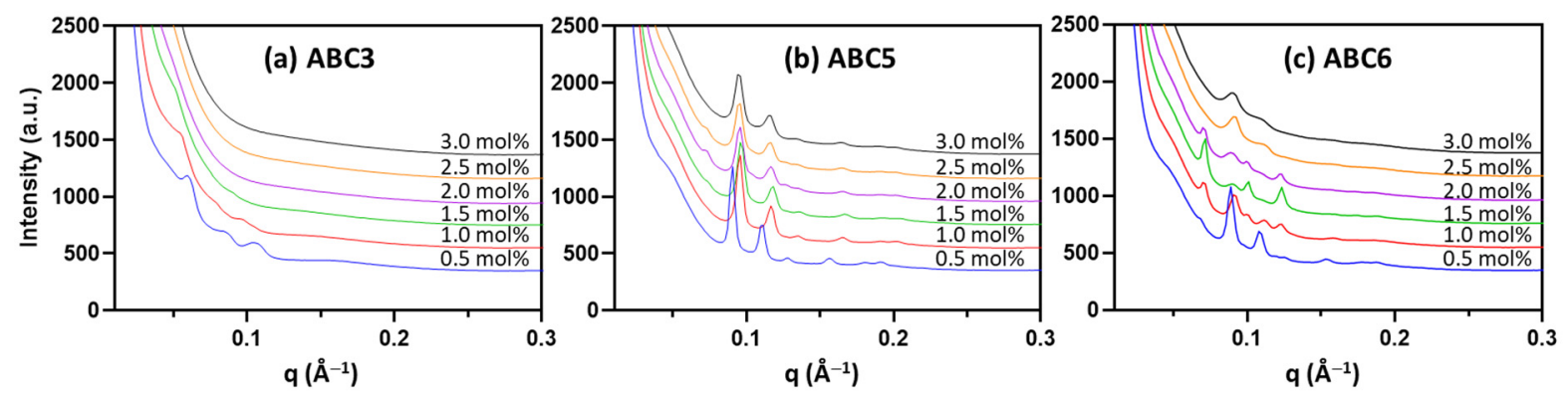

Figure 4. SAXS diffraction patterns of MO nanoparticles stabilized by PTBA-containing polymers, viz. ABC3 (a), ABC5 (b) and $\mathrm{ABC} 6$ (c) at various concentrations after incubation with $50 \mathrm{mM} \mathrm{H}_{2} \mathrm{O}_{2}$ solution. All measurements were performed at $25^{\circ} \mathrm{C}$.

Table 2. Mesophase identification and calculated lattice parameters $(\AA)$ of the MO nanoparticles stabilized by the synthetic ABCs in the presence of $50 \mathrm{mM} \mathrm{H}_{2} \mathrm{O}_{2}$.

\begin{tabular}{|c|c|c|c|}
\hline $\mathrm{mol} \%$ & $\mathrm{ABC} 3$ & $\mathrm{ABC} 5$ & $\mathrm{ABC} 6$ \\
\hline 0.5 & $\operatorname{Im} 3 \mathrm{~m}(148)$ & Pn3m (98) & Pn3m (100) \\
\hline 1.0 & $\operatorname{Im} 3 m(161)$ & Pn3m (92) & $\begin{array}{c}\operatorname{Im} 3 m(122) \\
\text { Pn3m (97) }\end{array}$ \\
\hline 1.5 & ND & Pn3m (91) & $\begin{array}{l}\text { Im3m (125) } \\
\text { Pn3m (100) }\end{array}$ \\
\hline 2.0 & ND & $\begin{array}{c}\text { Pn3m (93) } \\
\text { Im3m (weak) }\end{array}$ & $\begin{array}{l}\text { Im3m (120) } \\
\text { Pn3m (100) }\end{array}$ \\
\hline 2.5 & ND & $\begin{array}{c}\text { Pn3m (94) } \\
\text { (Im3m weak) }\end{array}$ & Pn3m (100) \\
\hline 3.0 & ND & Pn3m (94) & Pn3m (101) \\
\hline
\end{tabular}

Note: $\operatorname{Im} 3 m$ refers to the primitive $\mathrm{Q}_{\text {II }}\left(\mathrm{Q}_{\text {II }}{ }^{\mathrm{P}}\right)$ phase with symmetry group Im3m; Pn3m refers to the doublediamond $\mathrm{Q}_{\text {II }}\left(\mathrm{Q}_{\mathrm{II}}{ }^{\mathrm{D}}\right)$ phase with symmetry group Pn3m; ND refers to no distinctive diffraction pattern identified.

Figure 4a and Table 2 show that after incubating the ABC3-stabilized MO nanoparticles with $50 \mathrm{mM} \mathrm{H} \mathrm{O}_{2}$ for one hour, only those stabilized by low polymer concentrations $(0.5-1.0 \mathrm{~mol} \%)$ still retained the $\mathrm{Q}_{\mathrm{II}}{ }^{\mathrm{P}}$ phase. However, nanoparticles stabilized by $\mathrm{ABC} 3$ at $1.5 \mathrm{~mol} \%$ or higher concentrations lost the highly swollen $\mathrm{Q}_{\text {II }}{ }^{\mathrm{P}}$ phase observed in the absence of $\mathrm{H}_{2} \mathrm{O}_{2}$ (Table 1), indicating that the PTBA block started degrading. However, after $\mathrm{H}_{2} \mathrm{O}_{2}$ incubation, $\mathrm{ABC}$-stabilized $\mathrm{MO}$ nanoparticles favored the formation of the $\mathrm{Q}_{\text {II }}{ }^{\mathrm{D}}$ phase (Figure $4 \mathrm{~b}$; Table 2 ) instead of the $\mathrm{Q}_{\text {II }}{ }^{\mathrm{P}}$ phase found under normal conditions (Figure 3; Table 1). In the case of the $\mathrm{ABC} 6$ samples, the $\mathrm{Q}_{\mathrm{II}}{ }^{\mathrm{D}}$ phase also appeared in the polymer concentration range of $2.5-3.0 \mathrm{~mol} \%$ (Figure $4 \mathrm{c}$ ).

The $\mathrm{H}_{2} \mathrm{O}_{2}$-induced mesophase changes of the $\mathrm{MO}$ nanoparticles stabilized by $\mathrm{ABC} 5$ and $\mathrm{ABC} 6$ were most distinct at high polymer concentrations. Under normal buffer conditions, $\mathrm{ABC} 5(3.0 \mathrm{~mol} \%)$ and ABC6 (2.5-3.0 mol\%) could stabilize MO nanoparticles containing the $\mathrm{L}_{2}$ phase (Figure 3; Table 1). As shown by Figure $4 \mathrm{~b}, \mathrm{c}, \mathrm{H}_{2} \mathrm{O}_{2}$ incubation led to the transition from the $\mathrm{L}_{2}$ phase to the $\mathrm{Q}_{\mathrm{II}}{ }^{\mathrm{D}}$ phase. This mesophase transition clearly indicates a decrease of the negative membrane curvature, which can be attributed to the degradation of the hydrophobic PTBA group and less polymer insertion into the lipid matrix.

\section{4. pH-Responsiveness of the Formulated Nanoparticles}

PDMAEMA is a well-known dually-responsive functional block that changes water solubility in response to $\mathrm{pH}$ and temperature and therefore has been explored in many polymer-based drug delivery systems $[60,68]$. In the present study, the $\mathrm{pH}$ responsiveness of the LLC mesophase of the MO nanoparticles stabilized by $\mathrm{ABC} 4, \mathrm{ABC} 5$ and $\mathrm{ABC} 6$ (all containing the PDMAEMA block) was assessed at $\mathrm{pH}$ levels between 2 and 10. As a control, MO nanoparticles stabilized by ABC3 with no PDMAEMA block showed no 
mesophase changes with all formulations exhibiting the $\mathrm{Q}_{\mathrm{II}}{ }^{\mathrm{P}}$ phase in the $\mathrm{pH}$ range of 2-10 (Supplementary Information Figure S15).

The $\mathrm{pH}$-responsiveness of the MO nanoparticles stabilized by PDMAEMA-containing polymers depends on the polymer structure and concentration (Figure 5). For example, Figure 5a shows that $1.0 \mathrm{~mol} \% \mathrm{ABC} 4$ caused the internal LLC mesophase of the MO nanoparticles to transform from $\mathrm{Q}_{\text {II }}{ }^{\mathrm{P}}\left(\mathrm{pH}\right.$ ) to mixed $\mathrm{Q}_{\text {II }}^{\mathrm{P}} / \mathrm{Q}_{\text {II }}{ }^{\mathrm{D}}(\mathrm{pH} 4-7)$ to $\mathrm{Q}_{\text {II }}{ }^{\mathrm{D}}(\mathrm{pH}$ 8-10). At higher concentrations, the concentration effect of increasing the negative membrane curvature seemed to be the dominant effect as a large compositional space (2.0-3.0 mol\%, $\mathrm{pH} 2-6$ ) exhibited the $\mathrm{H}_{\text {II }}$ phase. It can also be observed that at $2.5-3 \mathrm{~mol} \% \mathrm{ABC}$, increasing $\mathrm{pH}$ caused a transition from $\mathrm{H}_{\text {II }}$ to mixed $\mathrm{H}_{\text {II }} / \mathrm{Q}_{\text {II }}{ }^{\mathrm{D}}$ at neutral $\mathrm{pH}$, which seemed to be in the opposite direction in terms of changing the membrane curvature compared to the $1.0 \mathrm{~mol} \%$ sample. This could be due to the complexity of the apparent $\mathrm{pK}_{\mathrm{a}}$ of the DMAEMA group which can depend on the polymer structure, the concentration in the system, the insertion into the membrane and the ionic strength of the buffer (further discussed in Section 3).
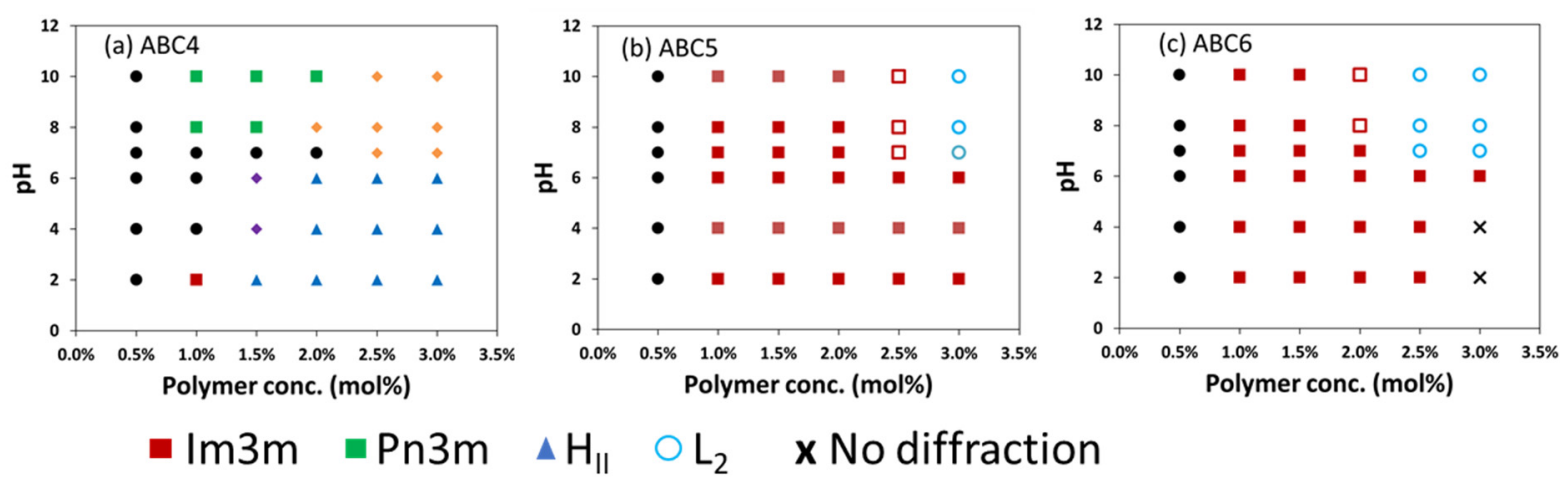

$\Delta \mathrm{H}_{\mathrm{II}}$ $\mathrm{O} \mathrm{L}_{2}$

$x$ No diffraction

Figure 5. Mesophases of MO nanoparticles stabilized by PDMAEMA-containing polymers, viz. ABC4 (a), ABC5 (b) and $\mathrm{ABC} 6$ (c) at various concentrations in $\mathrm{pH} 2$ to 10 . All measurements were performed at $25^{\circ} \mathrm{C}$.

Due to the presence of the extra hydrophobic block (PTBA), ABC5 (Figure 5b) and ABC6 (Figure 5c) could stabilize MO nanoparticles that resisted $\mathrm{pH}$-induced changes up to $2 \mathrm{~mol} \%$ and $1.5 \mathrm{~mol} \%$, respectively. At higher concentrations, increasing the $\mathrm{pH}$ caused the $\mathrm{Q}_{\mathrm{II}}{ }^{\mathrm{P}}$ to $\mathrm{L}_{2}$ mesophase transformation at around neutral $\mathrm{pH}$. A specific example is the sample stabilized by $2.5 \mathrm{~mol} \% \mathrm{ABC} 6$, which had the $\mathrm{Q}_{\mathrm{II}}^{\mathrm{P}}$ phase at $\mathrm{pH} 2-6$ and transited to the $\mathrm{L}_{2}$ phase at $\mathrm{pH} 7-10$. Overall, these results indicate that $\mathrm{pH}$-induced mesophase transitions in $\mathrm{MO}$ nanoparticles stabilized by the PDMAEMA-containing polymers occurs around neutral $\mathrm{pH}$ and increasing the $\mathrm{pH}$ leads to the formation of mesophases with higher negative membrane curvature.

\subsection{Temperature-Responsiveness of the Formulated Nanoparticles}

All previously described formulations (six polymers, six concentrations and seven buffer conditions) were screened by SAXS at three different temperatures, namely $25^{\circ} \mathrm{C}$, $37^{\circ} \mathrm{C}$ and $47^{\circ} \mathrm{C}$ (the highest sample environment temperature achievable at the synchrotron beamline), representing a total of 252 unique sample conditions. Due to the large number of data points, representative results are provided in Figure 6 to illustrate the effect of temperature on the mesophase behavior. In general, the mesophase behavior of the formulated nanoparticles with increasing temperature is as expected. Lipid self-assembly has intrinsic responsiveness to temperature as increasing temperature enhances hydrocarbon chain mobility and either reduces the lattice parameter of the unchanged mesophase or promotes a transition to a mesophase with higher interfacial negative curvature. As can be seen in the phase diagram of monoolein (MO) [69], a wedge-shaped molecule, increasing the temperature promotes the transition of $\mathrm{MO}$-water systems from the $\mathrm{Q}_{\text {II }}$ phase to the 
$\mathrm{H}_{\text {II }}$ phase. Numerous studies have also shown such temperature effect in nanoparticulate form $[45,54]$.
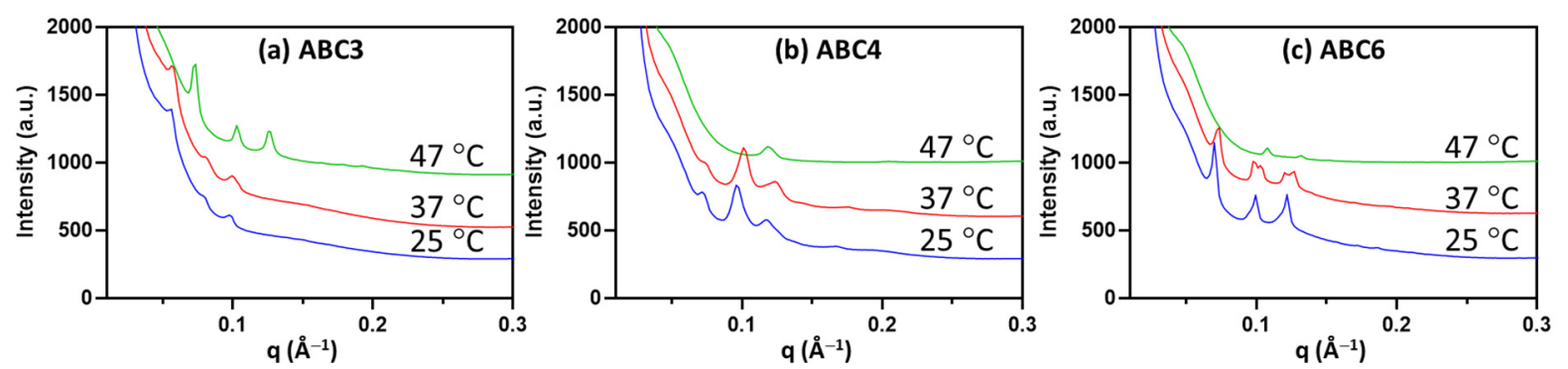

Figure 6. SAXS diffraction patterns of MO nanoparticles stabilized by $1.5 \mathrm{~mol} \% \mathrm{ABC} 3(\mathbf{a}), 1.5 \mathrm{~mol} \% \mathrm{ABC} 4(\mathbf{b})$ and $1.5 \mathrm{~mol} \%$ ABC6 (c) at neutral $\mathrm{pH}$ measured at three temperatures.

In this study, the temperature effect of increasing the negative membrane curvature is demonstrated by examples of MO nanoparticles stabilized by three polymers at $1.5 \mathrm{~mol} \%$ under neutral $\mathrm{pH}$ condition (Figure 6). Specifically in the case of the ABC3-stabilized MO nanoparticles, the lattice parameter of the $\mathrm{Q}_{\mathrm{II}}^{\mathrm{P}}$ phase reduced significantly from $157 \AA$ at $25^{\circ} \mathrm{C}$ and $37^{\circ} \mathrm{C}$ to $121 \AA$ at $47^{\circ} \mathrm{C}$, as can be seen from the diffraction peaks shifting to higher q values (Figure 6a). On the other hand, at $47^{\circ} \mathrm{C}, \mathrm{ABC}$-stabilized MO nanoparticles exhibited a cubic (mixed $\mathrm{Q}_{\text {II }}{ }^{\mathrm{P}} / \mathrm{Q}_{\text {II }}{ }^{\mathrm{D}}$ ) to $\mathrm{H}_{\text {II }}$ transition (Figure 6 b), while ABC6-stabilized nanoparticles exhibited a $\mathrm{Q}_{\text {II }} \mathrm{P}(a=126 \AA)$ to $\mathrm{Q}_{\text {II }}{ }^{\mathrm{D}}(a=83 \AA)$ phase transition.

\section{Discussion}

The concept of CPP has been frequently used to describe the shape of an amphiphilic molecule and predict the effect of amphiphilic additives on the LLC mesophase of lipidwater systems formed under specific conditions [55,70]. While the CPP of small molecule additives can be calculated using some standard equations, CPP estimation for large polymers such as $\mathrm{ABCs}$ can be more complex. Multiple steps of calculation and experimental measurement are required to derive CPP estimates for polymers. For example, the polymer chain "pervade" volume is derived from the radius of gyration or root-mean-square endto-end distance of the polymer chain. This is highly dependent on the solvent conditions. Experiments such as static light scattering and small-angle X-ray/neutron scattering are required to measure the radius of gyration. The polymer chain length can be estimated from the monomer units. However, it also depends on the folding/coiling of the chain. The effective area of the hydrophilic headgroup can also be measured experimentally or estimated theoretically. In general, the determination of CPP values for block copolymers is non-trivial. Nonetheless, the results reported herein, (Figure 1) show that the CPP is in the order of $\mathrm{ABC} 6>\mathrm{ABC} 5>\mathrm{ABC} 4>\mathrm{ABC} 3>\mathrm{ABC} 2>\mathrm{ABC} 1$ under neutral $\mathrm{PBS}$ conditions. This trend is as expected because all six $\mathrm{ABC}$ s have the same hydrophilic block ( $\mathrm{PEG}_{114}$ block), which presumably occupy the same headgroup area. $\mathrm{ABC} 1$ has the smallest $\mathrm{CPP}$ due to its small hydrophobic block $\left(\mathrm{C}_{12} \mathrm{H}_{25}\right)$ and substitution of $\mathrm{C}_{12} \mathrm{H}_{25}$ to the $\mathrm{PTBA}_{5-9}$ block (ABC2 and $\mathrm{ABC} 3$ ) leads to increased $\mathrm{CPP}$, attributable to the brush-like structures occupying larger volumes in the hydrophobic region. It is interesting to observe that adding a PDMAEMA 17 group can dramatically increase the CPP and promote higher membrane curvature (for example, ABC4 versus ABC1). Even though PDMAEMA is largely considered as hydrophilic, our results indicate that it at least partially interacted with the $\mathrm{MO}$ lipid bilayer and led to a mesophase transformation to the $\mathrm{H}_{\mathrm{II}}$ phase $(\mathrm{ABC}$ ) under neutral PBS conditions. This could be due to the increased backbone length. When both PTBA and PDMAEMA groups are present ( $\mathrm{ABC} 5$ and $\mathrm{ABC} 6$ ), there is a transformation to the $\mathrm{L}_{2}$ phase which possesses the highest negative membrane curvature, further confirming strong incorporation of the backbone into the membrane layer. The exact mechanism of the polymer-lipid interaction is unknown and needs further investigation. 
As a proof of concept, the responsiveness of the $\mathrm{ABC}$-stabilized $\mathrm{MO}$ nanoparticles was examined by changing environmental factors such as $\mathrm{H}_{2} \mathrm{O}_{2}, \mathrm{pH}$ and temperature. The PTBA block is degradable in response to $\mathrm{H}_{2} \mathrm{O}_{2}$ and given the hydrophobic nature of the PTBA block, $\mathrm{H}_{2} \mathrm{O}_{2}$-induced degradation is expected to lead to LLC mesophase changes as the polymer becomes more hydrophilic and the inserted PTBA region is eliminated [59]. Indeed, when the MO nanoparticles stabilized by PTBA-containing polymers were incubated in $50 \mathrm{mM} \mathrm{H}_{2} \mathrm{O}_{2}$, a reduction of the membrane curvature indicated by the mesophase transformation from $\mathrm{H}_{\text {II }}$ or $\mathrm{L}_{2}$ phase to $\mathrm{Q}_{\text {II }}$ phase was observed (Table 1 vs. Table 2). High concentrations of $\mathrm{H}_{2} \mathrm{O}_{2}$ is one of the hallmarks of the TME and has been exploited to design smart $\mathrm{H}_{2} \mathrm{O}_{2}$-responsive materials to enhance targeted drug delivery and tumor treatment efficiency [71]. Therefore, the current study illustrates the prospect of designing responsive LLC nanoparticle drug delivery systems. Transformation of the $\mathrm{H}_{\text {II }}$ or $\mathrm{L}_{2}$ phase with slow drug release to the $Q_{\text {II }}$ phase with high drug release rate [6] is desirable for systemic delivery where a burst release of drugs is only wanted at the tumour site.

The PDMAEMA moiety is $\mathrm{pH}$-sensitive and has a reported $\mathrm{pK}_{\mathrm{a}}$ around 7.3-7.5 in water [72]. The apparent $\mathrm{pK}_{\mathrm{a}}$ at the lipid-water interface will be different [73]. At low $\mathrm{pH}$, the moiety is protonated and the electrostatic repulsion between the surface charge groups should increase the occupied volume; at high $\mathrm{pH}$, the moiety is deprotonated and becomes more aggregated [72]. The change of the LLC mesophase will then largely depend on the location of the dimethylamino group in the MO lipid bilayer. In the case of ABC5 and ABC6 (2-3 $\mathrm{mol} \%$ ), increasing the $\mathrm{pH}$ led to a $\mathrm{Q}_{\text {II }}(\mathrm{pH} 2-6)$ to $\mathrm{L}_{2}$ transformation at around $\mathrm{pH} 7$, indicating that deprotonation of the dimethylamino group at higher $\mathrm{pH}$ reduces effective headgroup area and increases the membrane curvature. Such transformation behavior can offer advantages in enhancing drug release from the $Q_{\text {II }}$ phase in the slightly acidic TME [74] or enhancing the escape of the drug from the acidic endosomes/lysosomes [75]. While the current study needs optimization and further investigation of the lipid-polymer interaction, the value of the work lies in the successful demonstration of dually functional synthetic $\mathrm{ABC}$ s that can substitute for the commercial Pluronic polymer to stabilize non-lamellar LLC lipid nanoparticles, and impart responsiveness to physiologically and pathologically relevant $\mathrm{H}_{2} \mathrm{O}_{2}, \mathrm{pH}$ and temperature for controlled drug release.

\section{Materials and Methods}

\subsection{Materials}

MO was obtained from Nu-chek-Prep, Inc (Elysian, MN, USA) with purity $>99 \%$ according to the manufacturer's certificate. Phosphate buffer saline, ethanol and $\mathrm{H}_{2} \mathrm{O}_{2}$ solution $\left(30 \% w / w\right.$ in $\mathrm{H}_{2} \mathrm{O}$ ) were purchased from Sigma-Aldrich (Bayswater, Australia). Milli-Q water (18.2 M .cm) obtained from a Milli-Q Direct water purification system (Merck, Bayswater, Australia) was used for all sample preparations.

RAFT agent 4-cyano-4 (((dodecylthio)carbonothioyl)thio) pentanoic acid (CDPA; 97\%) was purchased from Boron Molecular (Noble Park, Australia). Poly(ethylene glycol) methyl ether $\left(\mathrm{PEG}_{114}\right.$, average $\left.M_{\mathrm{n}}=5000 \mathrm{~g} / \mathrm{mol}\right)$, 2-(dimethylamino)ethyl methacrylate (DMAEMA) and 1-methyl-1,4-cyclohexadiene were purchased from Sigma-Aldrich (Bayswater, Australia). 2,2'-Azobis(isobutyronitrile) (AIBN) and benzoyl peroxide were purchased from Wako Pure Chemical Industries, Ltd. The monomer 4-(4,4,5,5-tetramethyl1,3,2-dioxaborolan-2-yl)benzyl acrylate (TBA) was synthesized according to a procedure reported previously [59]. All other solvents were obtained from commercial sources and were used as received unless noted otherwise.

${ }^{1} \mathrm{H}$ Nuclear magnetic resonance spectra (NMR) were recorded on a Bruker Avance 400 NMR spectrometer at frequencies of $400 \mathrm{MHz}$. NMR chemical shifts $(\delta)$ are reported in ppm and were calibrated against residual solvent signal of $\mathrm{CDCl}_{3}(\delta 7.26)$. Samples were dissolved in $\mathrm{CDCl}_{3}$ at $5-10 \mathrm{mg} \mathrm{mL}^{-1}$. The data are reported as chemical shift ( $\left.\delta\right)$.

Gel permeation chromatography (GPC) was performed on a system comprising a Shimadzu LC-20AT pump, Shimadzu RID-20A refractive index detector, and SPD-20A UV-Visible detector. The GPC is equipped with a guard column (WAT054415) and 
$3 \times$ Waters GPC columns (WAT044238, WAT044226, WAT044235, $300 \mathrm{~mm} \times 7.8 \mathrm{~mm}$ ). The eluent is DMF with $10 \mathrm{mM} \mathrm{LiBr}$ and eluted at $1 \mathrm{~mL} / \mathrm{min}$ for $45 \mathrm{~min}$ in total. The columns were kept at $40^{\circ} \mathrm{C}$. The samples were dissolved in DMF with $10 \mathrm{mM} \mathrm{LiBr}$, filtered through $0.20 \mu \mathrm{m}$ syringe filters. A calibration curve was obtained from poly(methyl methacrylate) (PMMA) standards (Agilent, Mulgrave, Australia) ranging from 960 to 1,568,000 $\mathrm{g} \mathrm{mol}^{-1}$.

\subsection{Synthesis and Characterization of $A B C 1$ (PEG $114-R A F T)$}

The ABC1 (PEG 114 -RAFT) was synthesized via a procedure reported previously [63]. The sample was analyzed by ${ }^{1} \mathrm{H}$ NMR and GPC. ${ }^{1} \mathrm{H}$ NMR spectrum $\left(400 \mathrm{MHz} \mathrm{CDCl}_{3}\right)$ : $\delta 4.25(\mathrm{t}, 2 \mathrm{H}), 3.45-3.81(\mathrm{~m}, 412 \mathrm{H}), 3.36(\mathrm{~s}, 3 \mathrm{H}), 3.31(\mathrm{t}, 2 \mathrm{H}), 2.37-2.65(\mathrm{~m}, 4 \mathrm{H}), 1.86(\mathrm{~s}, 3 \mathrm{H})$, 1.69 (m, 2H), 1.25-1.38 (b, 18H), 0.86 (t, 3H). GPC (DMF, PMMA standards): $M_{\mathrm{n}}=12,300 \mathrm{~g} / \mathrm{mol}$, $Đ=1.08$.

\subsection{Synthesis and Characterization of $A B C 2\left(P E G_{114}-P T B A_{5}\right)$}

PEG $_{114}$-RAFT (300.0 mg, $55.6 \mu \mathrm{mol}, 1.0$ equiv.), TBA (96.1 mg, $333.6 \mu \mathrm{mol}, 6.0$ equiv.) and AIBN (1.8 mg, $11.1 \mu \mathrm{mol}, 0.2$ equiv.) were dissolved in $1.2 \mathrm{~mL} \mathrm{1,4-dioxane}$ and transferred to a Schlenk flask. The oxygen inside the flask was removed by 3 cycles of freeze-pump-thaw and refilled with argon in the third cycle. The reaction was stopped by cooling to room temperature after being immersed in a $65{ }^{\circ} \mathrm{C}$ oil bath for $20 \mathrm{~h}$. The synthesized $\mathrm{PEG}_{114}-\mathrm{PTBA}_{5}$-RAFT was purified by precipitation in hexane and dried under reduced pressure. To remove the RAFT end-group, the PEG $_{114}-\mathrm{PTBA}_{5}-\mathrm{RAFT}$, benzoyl peroxide $(35.4 \mathrm{mg}, 146.0 \mu \mathrm{mol})$ and 1-methyl-1,4-cyclohexadiene $(68.6 \mathrm{mg}, 730.0 \mu \mathrm{mol})$

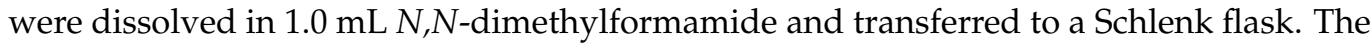
oxygen inside the flask was removed by 3 cycles of freeze-pump-thaw and refilled with argon in the third cycle. The reaction was stopped by cooling to room temperature after being immersed in a $100{ }^{\circ} \mathrm{C}$ oil bath for $4 \mathrm{~h}$. The polymer $\mathrm{PEG}_{114}-\mathrm{PTBA}_{5}$ was purified by precipitation in hexane and dried under reduced pressure. ${ }^{1} \mathrm{H}$ NMR spectrum $(400 \mathrm{MHz}$, $\left.\mathrm{CDCl}_{3}\right): \delta 7.77(\mathrm{~b}, 9 \mathrm{H}), 7.32(\mathrm{~b}, 9 \mathrm{H}), 5.06(\mathrm{~b}, 10 \mathrm{H}), 3.53-3.77(\mathrm{~b}, 457 \mathrm{H}), 3.38(\mathrm{~s}, 3 \mathrm{H}), 1.60-2.53$ (b, 40H), 1.33 (b, 50H). GPC (DMF, PMMA standards): $M_{\mathrm{n}}=13,500 \mathrm{~g} / \mathrm{mol}, \oplus=1.12$.

\subsection{Synthesis and Characterization of $A B C 3\left(P E G_{114}-P T B A_{9}\right)$}

ABC3 was synthesized in a similar procedure as ABC2. ${ }^{1} \mathrm{H}$ NMR spectrum $(400 \mathrm{MHz}$, $\left.\mathrm{CDCl}_{3}\right): \delta 7.76(\mathrm{~b}, 16 \mathrm{H}), 7.32(\mathrm{~b}, 18 \mathrm{H}), 4.99(\mathrm{~b}, 19 \mathrm{H}), 3.53-3.77(\mathrm{~b}, 455 \mathrm{H}), 3.38(\mathrm{~s}, 3 \mathrm{H})$, 1.60-2.53 (b, 27H), 1.31 (b, 86H). GPC (DMF, PMMA standards): $M_{\mathrm{n}}=13,900 \mathrm{~g} / \mathrm{mol}$, $Ð=1.14$.

\subsection{Synthesis and Characterization of ABC4 (PEG $\left.114-P D M A E M A_{17}-R A F T\right)$}

PEG $_{114}$-RAFT (1.0 g, 185.0 umol, 1.0 equiv.), DMAEMA (0.58 g, 3.7 mmol, 20.0 equiv.) and AIBN (6.1 mg, $37.0 \mu \mathrm{mol}, 0.2$ equiv.) were dissolved in $3.0 \mathrm{~mL} \mathrm{1,4-dioxane}$ and transferred to a Schlenk flask. The oxygen inside the flask was removed by 3 cycles of freeze-pump-thaw and refilled with argon in the third cycle. The reaction was stopped by cooling to room temperature after being immersed in a $60{ }^{\circ} \mathrm{C}$ oil bath for $24 \mathrm{~h}$. The synthesized PEG $_{114}$-PDMAEMA 17 -RAFT was purified by precipitation in hexane and dried under reduced pressure. ${ }^{1} \mathrm{H}$ NMR $\left(400 \mathrm{MHz}, \mathrm{CDCl}_{3}\right): \delta 3.99-4.16(\mathrm{~b}, 34 \mathrm{H}), 3.55-3.75(\mathrm{~b}$, $456 \mathrm{H}), 3.37$ (s, 3H), 2.52-2.71 (b, 39H), 2.18-2.44 (b, 112H), 1.57-2.04 (b, 39H), 1.18-1.37 (b, 24H), 0.82-1.15 (b, 51H). GPC (DMF, PMMA standards): $M_{\mathrm{n}}=12,700 \mathrm{~g} / \mathrm{mol}, \emptyset=1.17$.

\subsection{Synthesis and Characterization of ABC5 (PEG $\left.114-P D M A E M A_{17}-P T B A_{5}-R A F T\right)$}

$\mathrm{PEG}_{114}$-PDMAEMA 17 -RAFT (300.0 mg, $36.0 \mu \mathrm{mol}, 1.0$ equiv.), TBA (63.0 mg, $216.0 \mu \mathrm{mol}$, 6.0 equiv.) and $\mathrm{AIBN}(2.4 \mathrm{mg}, 14.4 \mu \mathrm{mol}, 0.4$ equiv.) were dissolved in $1.0 \mathrm{~mL}$ 1,4-dioxane and transferred to a Schlenk flask. The oxygen inside the flask was removed by 3 cycles of freeze-pump-thaw and refilled with argon in the third cycle. The reaction was stopped by cooling to room temperature after being immersed in a $65{ }^{\circ} \mathrm{C}$ oil bath for $24 \mathrm{~h}$. The synthesized PEG $_{114}$-PDMAEMA $17-$ PTBA $_{5}-$ RAFT was purified by precipitation in hexane and 
dried under reduced pressure. ${ }^{1} \mathrm{H}$ NMR $\left(400 \mathrm{MHz}, \mathrm{CDCl}_{3}\right): \delta 7.69-7.82(\mathrm{~b}, 8 \mathrm{H}), 7.26-7.36$ (b, 11H), 4.81-5.16 (b, 9H), 3.99-4.27 (b, 34H), 3.55-3.75 (b, 401H), $3.37(\mathrm{~s}, 3 \mathrm{H}), 2.55-2.75(\mathrm{~b}$, $30 \mathrm{H}), 2.16-2.52(\mathrm{~b}, 100 \mathrm{H}), 1.65-2.04(\mathrm{~b}, 35 \mathrm{H}), 1.18-1.39(\mathrm{~b}, 59 \mathrm{H}), 0.82-1.15(\mathrm{~b}, 47 \mathrm{H})$. GPC (DMF, PMMA standards): $M_{\mathrm{n}}=14,500 \mathrm{~g} / \mathrm{mol}, Ð=1.13$.

\subsection{Synthesis and Characterization of $A B C 6$ ( $\left.P E G_{114}-P D M A E M A_{17}-P T B A_{9}-R A F T\right)$}

$\mathrm{ABC} 6$ was synthesized in a similar procedure as $\mathrm{ABC} 5 .{ }^{1} \mathrm{H} \mathrm{NMR}\left(400 \mathrm{MHz}, \mathrm{CDCl}_{3}\right)$ : 8 7.69-7.83 (b, 16H), 7.26-7.36 (b, 13H), 4.81-5.16 (b, 19H), 3.99-4.27 (b, 38H), 3.55-3.75 (b, $456 \mathrm{H}), 3.37(\mathrm{~s}, 3 \mathrm{H}), 2.23-3.16(\mathrm{~b}, 189 \mathrm{H}), 1.65-2.04(\mathrm{~b}, 38 \mathrm{H}), 1.18-1.39(\mathrm{~b}, 99 \mathrm{H}), 0.82-1.15(\mathrm{~b}$, 56H). GPC (DMF, PMMA standards): $M_{\mathrm{n}}=15,300 \mathrm{~g} / \mathrm{mol}, Ð=1.14$.

\subsection{Formulation of ABC-Stabilized Nanoparticles}

$\mathrm{ABC}$-stabilized MO-based nanoparticles were prepared by adding $\mathrm{ABC}$ aqueous solutions to MO dry film, followed by sonication. Each formulation contained $20 \mathrm{mg}$ of $\mathrm{MO}$, which was first dissolved in ethanol and then evaporated overnight using a vacuum oven at $40{ }^{\circ} \mathrm{C}$ to obtain the dry lipid film. ABCs were solubilized in PBS buffer and equilibrated at room temperature for at least $48 \mathrm{~h}$. $\mathrm{ABC}$ solutions were added to $\mathrm{MO}$ at $0.5 \%, 1.0 \%, 1.5 \%, 2.0 \%, 2.5 \%$ and $3.0 \%(\mathrm{~mol} / \mathrm{mol})$ to $\mathrm{MO}$. The final sample volume was kept at $0.5 \mathrm{~mL}$. Samples were then sonicated using a probe sonicator (Qsonica, Newtown, CT, USA) at a frequency of $30 \mathrm{kHz}$, with a $5 \mathrm{~s}$ on, $5 \mathrm{~s}$ off mode for a total sonication time of $2 \mathrm{~min}$. Freshly prepared samples were examined visually and their dispersibility and appearance were recorded (Table S1).

To examine the $\mathrm{H}_{2} \mathrm{O}_{2}$ and $\mathrm{pH}$ responsiveness of the internal LLC mesophase of the formed nanoparticles, pre-made nanoparticles were diluted (1:1 ratio) with either $50 \mathrm{mM}$ $\mathrm{H}_{2} \mathrm{O}_{2}$ solution, or PBS buffer with adjusted $\mathrm{pH}$ levels between 2 to 10 using hydrogen chloride or sodium hydroxide solution. The samples were incubated for one hour before SAXS examination.

To examine the temperature responsiveness, nanoparticle samples were mounted to the custom-designed plate holder at the SAXS/WAXS beamline at the Australian Synchrotron, and temperature was controlled in situ by a circulating water bath for scanning at $25^{\circ} \mathrm{C}, 37^{\circ} \mathrm{C}$ and $47^{\circ} \mathrm{C}$.

\subsection{High Throughput Synchrotron SAXS Characterization}

The SAXS experiment was performed at the SAXS/WAXS beamline at the Australian Synchrotron, part of ANSTO. The beamline used X-ray of wavelength $\lambda=1.033 \AA(12.0 \mathrm{keV})$ with a typical flux of approximately $10^{13}$ photons/s. The sample to detector distance was chosen as $1.6 \mathrm{~m}$ which provided a $q$-range of $0.01-0.5 \AA^{-1}$ (scattering vector $q=4 \pi \sin (\theta) / \lambda$ where $\theta$ is the scattering angle and $\lambda$ is the wavelength). Two-dimensional $\mathrm{X}$-ray diffraction images were recorded on a Decris-Pilatus 1-M detector using an in-house IDL-based ScatterBrain software. The scattering images were integrated into one dimensional plots of intensity versus $q$ for phase identification. A silver behenate standard $(d=58.38 \AA$ ) was used for calibration. The exposure time for each sample was $1 \mathrm{~s}$. Prepared nanoparticles $(100 \mu \mathrm{L})$ were loaded in UV-clear half-area 96-well microplate (Greiner Bio-One) and mounted to the high throughput sample-holder at the beamline.

\subsection{SAXS Data Analysis}

The one-dimensional SAXS data were analyzed using an IDL-based AXcess software package [76]. This program identifies LLC mesophases and calculates the lattice parameter. Phase identification was based on the relative distance of the Bragg peaks in the scattering profile, which corresponds to diffraction planes defined by their $(h k l)$ Miller indices. Lattice parameter (a) was calculated using the equation $a=d\left(h^{2}+k^{2}+l^{2}\right)^{1 / 2}$ for cubic phase or $a=d\left(h^{2}+k^{2}+h k\right)^{1 / 2}$ for hexagonal phase where $d$ is the spacing between the diffraction planes, defined by Bragg's law $d=2 \pi / q$. 


\section{Conclusions}

In this study, a series of dual-functional ABCs was designed containing a hydrophobic part to partition into lipid layers, a hydrophilic part to exert steric stabilization for nanoparticle dispersions and a PTBA and/or PDMAEMA group that could respond to environmental factors. Using high throughput formulation and synchrotron SAXS techniques, we have successfully demonstrated that the synthetic $\mathrm{ABC}$ could stabilize $\mathrm{MO}$ nanoparticles containing a range of LLC mesophases, which can respond to $\mathrm{H}_{2} \mathrm{O}_{2}, \mathrm{pH}$ and temperature. Notably, a mesophase transformation from the slow drug release $\mathrm{H}_{\mathrm{II}} / \mathrm{L}_{2}$ phase to the high drug release $\mathrm{Q}_{\text {II }}$ phase can be induced in PTBA- or PDMAEMA-containing polymer-based nanoparticles under elevated $\mathrm{H}_{2} \mathrm{O}_{2}$ or acidic $\mathrm{pH}$ conditions, which are hallmarks of disease sites such as tumors. Future studies are planned to investigate model drug loading and release using these stimuli-responsive non-lamellar lipid nanoparticles, as well as cytotoxicity, cellular uptake and endosomal escape. The findings in this study may pave a new path to develop stimuli-responsive lipid nanoparticles that can promote drug release at specific target sites and enhance therapeutic efficacy.

Supplementary Materials: The following are available online. Table S1: Visual examination of the nanoparticles stabilized by the synthetic polymers, Table S2: Particle size and size distribution of the nanoparticles measured by DLS, Figures S1-S12: ${ }^{1} \mathrm{H}$ NMR and GPC data of the synthesized polymers, Figure S13: Representative mesophase identification, Figure S14: SAXS diffraction patterns of ABC4-stabilized nanoparticles under $\mathrm{H}_{2} \mathrm{O}_{2}$ condition, Figure S15: pH-composition partial phase diagram of ABC3-stabilized nanoparticles.

Author Contributions: Conceptualization, J.Z., B.F.; data acquisition and curation, J.Z., B.F.; writingoriginal draft preparation, J.Z.; writing — review and editing, B.F., S.H.T., C.J.D., funding acquisition, S.H.T., C.J.D. All authors have read and agreed to the published version of the manuscript.

Funding: This research received no external funding. J.Z. is the recipient of an RMIT Research Fellowship.

Data Availability Statement: The data presented in this study are available on request from the corresponding author.

Acknowledgments: This research was undertaken on the SAXS/WAXS beamline at the Australian Synchrotron, part of ANSTO. We also thank all the beamline scientists, especially Nigel Kirby and Stephen Mudie, for their help at the facility.

Conflicts of Interest: The authors declare no conflict of interest.

Sample Availability: Samples of the compounds, monoolein and the polymers are available from the authors.

\section{References}

1. Barauskas, J.; Johnsson, M.; Joabsson, F.; Tiberg, F. Cubic phase nanoparticles (cubosome): Principles for controlling size, structure, and stability. Langmuir 2005, 21, 2569-2577. [CrossRef] [PubMed]

2. Dong, Y.-D.; Larson, I.; Hanley, T.; Boyd, B.J. Bulk and Dispersed Aqueous Phase Behavior of Phytantriol: Effect of Vitamin E Acetate and F127 Polymer on Liquid Crystal Nanostructure. Langmuir 2006, 22, 9512-9518. [CrossRef] [PubMed]

3. Tilley, A.J.; Drummond, C.J.; Boyd, B.J. Disposition and association of the steric stabilizer Pluronic ${ }^{\circledR}$ F127 in lyotropic liquid crystalline nanostructured particle dispersions. J. Colloid Interface Sci. 2013, 392, 288-296. [CrossRef] [PubMed]

4. Mulet, X.; Boyd, B.J.; Drummond, C.J. Advances in drug delivery and medical imaging using colloidal lyotropic liquid crystalline dispersions. J. Colloid Interface Sci. 2013, 393, 1-20. [CrossRef] [PubMed]

5. Barriga, H.M.G.; Holme, M.N.; Stevens, M.M. Cubosomes: The Next Generation of Smart Lipid Nanoparticles? Angew. Chem. Int. Ed. 2019, 58, 2958-2978. [CrossRef]

6. Zhai, J.; Fong, C.; Tran, N.; Drummond, C.J. Non-Lamellar Lyotropic Liquid Crystalline Lipid Nanoparticles for the Next Generation of Nanomedicine. ACS Nano 2019, 13, 6178-6206. [CrossRef]

7. Sagalowicz, L.; Michel, M.; Adrian, M.; Frossard, P.; Rouvet, M.; Watzke, H.J.; Yaghmur, A.; De Campo, L.; Glatter, O.; Leser, M.E. Crystallography of dispersed liquid crystalline phases studied by cryo-transmission electron microscopy. J. Microsc. 2006, 221, 110-121. [CrossRef]

8. Seddon, J.M. Structure of the inverted hexagonal (HII) phase, and non-lamellar phase transitions of lipids. Biochim. Biophys. Acta Rev. Biomembr. 1990, 1031, 1-69. [CrossRef] 
9. Demurtas, D.; Guichard, P.; Martiel, I.; Mezzenga, R.; Hebert, C.; Sagalowicz, L. Direct visualization of dispersed lipid bicontinuous cubic phases by cryo-electron tomography. Nat. Commun. 2015, 6, 8915. [CrossRef] [PubMed]

10. Fong, W.-K.; Sanchez-Ferrer, A.; Ortelli, F.G.; Sun, W.; Boyd, B.J.; Mezzenga, R. Dynamic formation of nanostructured particles from vesicles via invertase hydrolysis for on-demand delivery. RSC Adv. 2017, 7, 4368-4377. [CrossRef]

11. Zhai, J.; Luwor, R.B.; Ahmed, N.; Escalona, R.; Tan, F.H.; Fong, C.; Ratcliffe, J.; Scoble, J.A.; Drummond, C.J.; Tran, N. PaclitaxelLoaded Self-Assembled Lipid Nanoparticles as Targeted Drug Delivery Systems for the Treatment of Aggressive Ovarian Cancer. ACS Appl. Mater. Interfaces 2018, 10, 25174-25185. [CrossRef] [PubMed]

12. Jain, V.; Swarnakar, N.K.; Mishra, P.R.; Verma, A.; Kaul, A.; Mishra, A.K.; Jain, N.K. Paclitaxel loaded PEGylated gleceryl monooleate based nanoparticulate carriers in chemotherapy. Biomaterials 2012, 33, 7206-7220. [CrossRef] [PubMed]

13. Yaghmur, A.; Mu, H. Recent advances in drug delivery applications of cubosomes, hexosomes, and solid lipid nanoparticles. Acta Pharm. Sin. B 2021, 11, 871-885. [CrossRef] [PubMed]

14. Lopes, L.B.; Ferreira, D.A.; de Paula, D.; Garcia, M.T.J.; Thomazini, J.A.; Fantini, M.C.; Bentley, M.V.L. Reverse hexagonal phase nanodispersion of monoolein and oleic acid for topical delivery of peptides: In vitro and in vivo skin penetration of cyclosporin A. Pharm. Res. 2006, 23, 1332-1342. [CrossRef] [PubMed]

15. Kim, H.; Leal, C. Cuboplexes: Topologically Active siRNA Delivery. ACS Nano 2015, 9, 10214-10226. [CrossRef]

16. Jenni, S.; Picci, G.; Fornasier, M.; Mamusa, M.; Schmidt, J.; Talmon, Y.; Sour, A.; Heitz, V.; Murgia, S.; Caltagirone, C. Multifunctional cubic liquid crystalline nanoparticles for chemo- and photodynamic synergistic cancer therapy. Photochem. Photobiol. Sci. 2020, 19, 674-680. [CrossRef] [PubMed]

17. Wu, H.; Cui, Z.; Huo, Y.; Sun, Y.; Zhang, X.; Guan, J.; Mao, S. Influence of drug-carrier compatibility and preparation method on the properties of paclitaxel-loaded lipid liquid crystalline nanoparticles. J. Pharm. Sci. 2021. [CrossRef] [PubMed]

18. Zhang, L.; Li, J.; Tian, D.; Sun, L.; Wang, X.; Tian, M. Theranostic combinatorial drug-loaded coated cubosomes for enhanced targeting and efficacy against cancer cells. Cell Death Dis. 2020, 11, 1. [CrossRef]

19. Tran, N.; Bye, N.; Moffat, B.A.; Wright, D.K.; Cuddihy, A.; Hinton, T.M.; Hawley, A.M.; Reynolds, N.P.; Waddington, L.J.; Mulet, X.; et al. Dual-modality NIRF-MRI cubosomes and hexosomes: High throughput formulation and in vivo biodistribution. Mater. Sci. Eng. C 2017, 71, 584-593. [CrossRef]

20. Bye, N.; Hutt, O.E.; Hinton, T.M.; Acharya, D.P.; Waddington, L.J.; Moffat, B.A.; Wright, D.K.; Wang, H.X.; Mulet, X.; Muir, B.W. Nitroxide-Loaded Hexosomes Provide MRI Contrast in Vivo. Langmuir 2014, 30, 8898-8906. [CrossRef]

21. Muir, B.W.; Acharya, D.P.; Kennedy, D.F.; Mulet, X.; Evans, R.A.; Pereira, S.M.; Wark, K.L.; Boyd, B.J.; Nguyen, T.-H.; Hinton, T.M.; et al. Metal-free and MRI visible theranostic lyotropic liquid crystal nitroxide-based nanoparticles. Biomaterials 2012, 33 , 2723-2733. [CrossRef]

22. Fong, W.-K.; Negrini, R.; Vallooran, J.J.; Mezzenga, R.; Boyd, B.J. Responsive self-assembled nanostructured lipid systems for drug delivery and diagnostics. J. Colloid Interface Sci. 2016, 484, 320-339. [CrossRef] [PubMed]

23. Yaghmur, A.; Glatter, O. Characterization and potential applications of nanostructured aqueous dispersions. Adv. Colloid Interface Sci. 2009, 147-148, 333-342. [CrossRef] [PubMed]

24. Boyd, B.J.; Rizwan, S.B.; Dong, Y.-D.; Hook, S.; Rades, T. Self-assembled geometric liquid-crystalline nanoparticles imaged in three dimensions: Hexosomes are not necessarily flat hexagonal prisms. Langmuir 2007, 23, 12461-12464. [CrossRef]

25. Mulet, X.; Kennedy, D.F.; Conn, C.E.; Hawley, A.; Drummond, C.J. High throughput preparation and characterisation of amphiphilic nanostructured nanoparticulate drug delivery vehicles. Int. J. Pharm. 2010, 395, 290-297. [CrossRef]

26. Sarkar, S.; Tran, N.; Soni, S.K.; Nasa, Z.; Drummond, C.J.; Conn, C.E. Cuboplex-Mediated Nonviral Delivery of Functional siRNA to Chinese Hamster Ovary (CHO) Cells. ACS Appl. Mater. Interfaces 2021, 13, 2336-2345. [CrossRef]

27. Boge, L.; Bysell, H.; Ringstad, L.; Wennman, D.; Umerska, A.; Cassisa, V.; Eriksson, J.; Joly-Guillou, M.-L.; Edwards, K.; Andersson, M. Lipid-Based Liquid Crystals As Carriers for Antimicrobial Peptides: Phase Behavior and Antimicrobial Effect. Langmuir 2016, 32, 4217-4228. [CrossRef]

28. Angelova, A.; Angelov, B.; Mutafchieva, R.; Lesieur, S.; Couvreur, P. Self-Assembled Multicompartment Liquid Crystalline Lipid Carriers for Protein, Peptide, and Nucleic Acid Drug Delivery. Acc. Chem. Res. 2010, 44, 147-156. [CrossRef]

29. Géral, C.; Angelova, A.; Lesieur, S. From Molecular to Nanotechnology Strategies for Delivery of Neurotrophins: Emphasis on Brain-Derived Neurotrophic Factor (BDNF). Pharmaceutics 2013, 5, 127-167. [CrossRef] [PubMed]

30. Negrini, R.; Fong, W.-K.; Boyd, B.J.; Mezzenga, R. pH-responsive lyotropic liquid crystals and their potential therapeutic role in cancer treatment. Chem. Commun. 2015, 51, 6671-6674. [CrossRef] [PubMed]

31. Vallooran, J.J.; Handschin, S.; Bolisetty, S.; Mezzenga, R. Twofold Light and Magnetic Responsive Behavior in NanoparticleLyotropic Liquid Crystal Systems. Langmuir 2012, 28, 5589-5595. [CrossRef] [PubMed]

32. Szlezak, M.; Nieciecka, D.; Joniec, A.; Pękała, M.; Gorecka, E.; Emo, M.; Stébé, M.J.; Krysiński, P.; Bilewicz, R. Monoolein Cubic Phase Gels and Cubosomes Doped with Magnetic Nanoparticles-Hybrid Materials for Controlled Drug Release. ACS Appl. Mater. Interfaces 2017, 9, 2796-2805. [CrossRef] [PubMed]

33. Li, Y.; Angelova, A.; Hu, F.; Garamus, V.M.; Peng, C.; Li, N.; Liu, J.; Liu, D.; Zou, A. pH Responsiveness of Hexosomes and Cubosomes for Combined Delivery of Brucea javanica Oil and Doxorubicin. Langmuir 2019, 35, 14532-14542. [CrossRef]

34. Zhai, J.; Tan, F.H.; Luwor, R.B.; Srinivasa Reddy, T.; Ahmed, N.; Drummond, C.J.; Tran, N. In Vitro and In Vivo Toxicity and Biodistribution of Paclitaxel-Loaded Cubosomes as a Drug Delivery Nanocarrier: A Case Study Using an A431 Skin Cancer Xenograft Model. ACS Appl. Bio Mater. 2020, 3, 4198-4207. [CrossRef] 
35. Abdelrahman, F.E.; Elsayed, I.; Gad, M.K.; Badr, A.; Mohamed, M.I. Investigating the cubosomal ability for transnasal brain targeting: In vitro optimization, ex vivo permeation and in vivo biodistribution. Int. J. Pharm. 2015, 490, 281-291. [CrossRef]

36. Nasr, M.; Ghorab, M.K.; Abdelazem, A. In vitro and in vivo evaluation of cubosomes containing 5-fluorouracil for liver targeting. Acta Pharm. Sin. B 2015, 5, 79-88. [CrossRef] [PubMed]

37. Stefania, B.; Laura, A.; Claudia, C.; Chiara, G.; Angela, M.F.; Vito, L.; Andrea, L.; Paolo, M.; Valeria, M.; Maura, M.; et al. Cubosomes for in vivo fluorescence lifetime imaging. Nanotechnology 2017, 28, 055102.

38. Fong, W.K.; Hanley, T.; Boyd, B.J. Stimuli responsive liquid crystals provide 'on-demand' drug delivery in vitro and in vivo. J. Control Release 2009, 135, 218-226. [CrossRef] [PubMed]

39. Negrini, R.; Mezzenga, R. pH-Responsive Lyotropic Liquid Crystals for Controlled Drug Delivery. Langmuir 2011, $27,5296-5303$. [CrossRef]

40. Rahanyan-Kagi, N.; Aleandri, S.; Speziale, C.; Mezzenga, R.; Landau, E.M. Stimuli-responsive lipidic cubic phase: Triggered release and sequestration of guest molecules. Chemistry 2015, 21, 1873-1877. [CrossRef]

41. Rarokar, N.R.; Saoji, S.D.; Raut, N.A.; Taksande, J.B.; Khedekar, P.B.; Dave, V.S. Nanostructured Cubosomes in a Thermoresponsive Depot System: An Alternative Approach for the Controlled Delivery of Docetaxel. AAPS PharmSciTech 2016, 17, 436-445. [CrossRef] [PubMed]

42. Lee, K.W.Y.; Nguyen, T.-H.; Hanley, T.; Boyd, B.J. Nanostructure of liquid crystalline matrix determines in vitro sustained release and in vivo oral absorption kinetics for hydrophilic model drugs. Int. J. Pharm. 2009, 365, 190-199. [CrossRef] [PubMed]

43. Tran, N.; Mulet, X.; Hawley, A.M.; Hinton, T.M.; Mudie, S.T.; Muir, B.W.; Giakoumatos, E.C.; Waddington, L.J.; Kirby, N.M.; Drummond, C.J. Nanostructure and cytotoxicity of self-assembled monoolein-capric acid lyotropic liquid crystalline nanoparticles. RSC Adv. 2015, 5, 26785-26795. [CrossRef]

44. Mertins, O.; Mathews, P.D.; Angelova, A. Advances in the Design of pH-Sensitive Cubosome Liquid Crystalline Nanocarriers for Drug Delivery Applications. Nanomaterials 2020, 10, 963. [CrossRef] [PubMed]

45. Tran, N.; Hawley, A.M.; Zhai, J.; Muir, B.W.; Fong, C.; Drummond, C.J.; Mulet, X. High-throughput screening of saturated fatty acid influence on nanostructure of lyotropic liquid crystalline lipid nanoparticles. Langmuir 2016, 32, 4509-4520. [CrossRef]

46. Fong, C.; Zhai, J.; Drummond, C.J.; Tran, N. Micellar Fd3m cubosomes from monoolein-long chain unsaturated fatty acid mixtures: Stability on temperature and $\mathrm{pH}$ response. J. Colloid Interface Sci. 2020, 566, 98-106. [CrossRef]

47. Rajesh, S.; Zhai, J.; Drummond, C.J.; Tran, N. Synthetic ionizable aminolipids induce a pH dependent inverse hexagonal to bicontinuous cubic lyotropic liquid crystalline phase transition in monoolein nanoparticles. J. Colloid Interface Sci. 2021, 589, 85-95. [CrossRef] [PubMed]

48. Israelachvili, J.N.; Mitchell, D.J.; Ninham, B.W. Theory of self-assembly of hydrocarbon amphiphiles into micelles and bilayers. J. Chem. Soc. Faraday Trans. 2 Mol. Chem. Phys. 1976, 72, 1525-1568. [CrossRef]

49. Chong, J.Y.T.; Mulet, X.; Boyd, B.J.; Drummond, C.J. Chapter Five-Steric Stabilizers for Cubic Phase Lyotropic Liquid Crystal Nanodispersions (Cubosomes). In Advances in Planar Lipid Bilayers and Liposomes; Iglič, A., Kulkarni, C.V., Rappolt, M., Eds.; Academic Press: Waltham, MA, USA, 2015; pp. 131-187.

50. Zhai, J.; Suryadinata, R.; Luan, B.; Tran, N.; Hinton, T.M.; Ratcliffe, J.; Hao, X.; Drummond, C.J. Amphiphilic brush polymers produced using the RAFT polymerisation method stabilise and reduce the cell cytotoxicity of lipid lyotropic liquid crystalline nanoparticles. Faraday Discuss. 2016, 191, 545-563. [CrossRef]

51. Chong, J.Y.T.; Mulet, X.; Keddie, D.J.; Waddington, L.; Mudie, S.T.; Boyd, B.J.; Drummond, C.J. Novel Steric Stabilizers for Lyotropic Liquid Crystalline Nanoparticles: PEGylated-Phytanyl Copolymers. Langmuir 2015, 31, 2615-2629. [CrossRef]

52. Yu Helvig, S.; Woythe, L.; Pham, S.; Bor, G.; Andersen, H.; Moein Moghimi, S.; Yaghmur, A. A structurally diverse library of glycerol monooleate/oleic acid non-lamellar liquid crystalline nanodispersions stabilized with nonionic methoxypoly(ethylene glycol) (mPEG)-lipids showing variable complement activation properties. J. Colloid Interface Sci. 2021, 582, 906-917. [CrossRef]

53. Angelov, B.; Angelova, A.; Drechsler, M.; Garamus, V.M.; Mutafchieva, R.; Lesieur, S. Identification of large channels in cationic PEGylated cubosome nanoparticles by synchrotron radiation SAXS and Cryo-TEM imaging. Soft Matter 2015, 11, 3686-3692. [CrossRef] [PubMed]

54. Zhai, J.; Waddington, L.; Wooster, T.J.; Aguilar, M.I.; Boyd, B.J. Revisiting $\beta$-casein as a stabilizer for lipid liquid crystalline nanostructured particles. Langmuir 2011, 27, 14757-14766. [CrossRef] [PubMed]

55. Zhai, J.; Hinton, T.M.; Waddington, L.J.; Fong, C.; Tran, N.; Mulet, X.; Drummond, C.J.; Muir, B.W. Lipid-PEG Conjugates Sterically Stabilize and Reduce the Toxicity of Phytantriol-Based Lyotropic Liquid Crystalline Nanoparticles. Langmuir 2015, 31, 10871-10880. [CrossRef] [PubMed]

56. Lee, Y.; Sugihara, K.; Gillilland, M.G.; Jon, S.; Kamada, N.; Moon, J.J. Hyaluronic acid-bilirubin nanomedicine for targeted modulation of dysregulated intestinal barrier, microbiome and immune responses in colitis. Nat. Mater. 2020, 19, 118-126. [CrossRef] [PubMed]

57. Fornasier, M.; Biffi, S.; Bortot, B.; Macor, P.; Manhart, A.; Wurm, F.R.; Murgia, S. Cubosomes stabilized by a polyphosphoesteranalog of Pluronic F127 with reduced cytotoxicity. J. Colloid Interface Sci. 2020, 580, 286-297. [CrossRef]

58. Chountoulesi, M.; Perinelli, D.R.; Pippa, N.; Chrysostomou, V.; Forys, A.; Otulakowski, L.; Bonacucina, G.; Trzebicka, B.; Pispas, S.; Demetzos, C. Physicochemical, morphological and thermal evaluation of lyotropic lipidic liquid crystalline nanoparticles: The effect of stimuli-responsive polymeric stabilizer. Colloids Surf. A 2020, 595, 124678. [CrossRef] 
59. Fan, B.; Wan, J.; Zhai, J.; Chen, X.; Thang, S.H. Triggered Degradable Colloidal Particles with Ordered Inverse Bicontinuous Cubic and Hexagonal Mesophases. ACS Nano 2021, 15, 4688-4698. [CrossRef]

60. Stubbs, E.; Laskowski, E.; Conor, P.; Heinze, D.A.; Karis, D.; Glogowski, E.M. Control of pH- and temperature-responsive behavior of mPEG-b-PDMAEMA copolymers through polymer composition. J. Macromol. Sci. Part A 2017, 54, 228-235. [CrossRef]

61. Mezzenga, R.; Seddon, J.M.; Drummond, C.J.; Boyd, B.J.; Schröder-Turk, G.E.; Sagalowicz, L. Nature-Inspired Design and Application of Lipidic Lyotropic Liquid Crystals. Adv. Mater. 2019, 31, 1900818. [CrossRef]

62. Mulet, X.; Conn, C.E.; Fong, C.; Kennedy, D.F.; Moghaddam, M.J.; Drummond, C.J. High-throughput development of amphiphile self-assembly materials: Fast-tracking synthesis, characterization, formulation, application, and understanding. Acc. Chem. Res. 2013, 46, 1497-1505. [CrossRef]

63. Wan, J.; Fan, B.; Liu, Y.; Hsia, T.; Qin, K.; Junkers, T.; Teo, B.M.; Thang, S.H. Room temperature synthesis of block copolymer nanoobjects with different morphologies via ultrasound initiated RAFT polymerization-induced self-assembly (sono-RAFT-PISA). Polym. Chem. 2020, 11, 3564-3572. [CrossRef]

64. Fan, B.; Wan, J.; McKay, A.; Qu, Z.; Thang, S.H. Facile synthesis of well-controlled poly(1-vinyl imidazole) by the RAFT process. Polym. Chem. 2020, 11, 5649-5658. [CrossRef]

65. Fan, B.; Wan, J.; Liu, Y.; Tian, W.W.; Thang, S.H. Functionalization of liquid metal nanoparticles via the RAFT process. Polym. Chem. 2021, 12, 3015-3025. [CrossRef]

66. Fan, B.; Liu, Y.; Wan, J.; Crawford, S.; Thang, S.H. Polymerization-Induced Self-Assembly (PISA) and "Host-Guest" ComplexationDirected Polymer/Gold Nanocomposites. ACS Mater. Lett. 2020, 2, 492-498. [CrossRef]

67. Tran, N.; Mulet, X.; Hawley, A.M.; Fong, C.; Zhai, J.; Le, T.C.; Ratcliffe, J.; Drummond, C.J. Manipulating the Ordered Nanostructure of Self-Assembled Monoolein and Phytantriol Nanoparticles with Unsaturated Fatty Acids. Langmuir 2018, 34, $2764-2773$. [CrossRef] [PubMed]

68. Chrysostomou, V.; Pispas, S. Stimuli-responsive amphiphilic PDMAEMA-b-PLMA copolymers and their cationic and zwitterionic analogs. J. Polym. Sci. Part A Polym. Chem. 2018, 56, 598-610. [CrossRef]

69. Clogston, J.; Rathman, J.; Tomasko, D.; Walker, H.; Caffrey, M. Phase behavior of a monoacylglycerol: (Myverol 18-99K)/water system. Chem. Phys. Lipids 2000, 107, 191-220. [CrossRef]

70. Van't Hag, L.; Gras, S.L.; Conn, C.E.; Drummond, C.J. Lyotropic liquid crystal engineering moving beyond binary compositional space-ordered nanostructured amphiphile self-assembly materials by design. Chem. Soc. Rev. 2017, 46, 2705-2731. [CrossRef] [PubMed]

71. Yang, N.; Xiao, W.; Song, X.; Wang, W.; Dong, X. Recent Advances in Tumor Microenvironment Hydrogen Peroxide-Responsive Materials for Cancer Photodynamic Therapy. Nano-Micro Lett. 2020, 12, 15. [CrossRef]

72. Loh, X.J.; Ong, S.J.; Tung, Y.T.; Choo, H.T. Dual responsive micelles based on poly[(R)-3-hydroxybutyrate] and poly(2-(dimethylamino)ethyl methacrylate) for effective doxorubicin delivery. Polym. Chem. 2013, 4, 2564-2574. [CrossRef]

73. Drummond, C.J.; Grieser, F.; Healy, T.W. Acid-base equilibria in aqueous micellar solutions. Part 1.-_'Simple' weak acids and bases. J. Chem. Soc. Faraday Trans. I 1989, 85, 521-535. [CrossRef]

74. Tannock, I.F.; Rotin, D. Acid pH in tumors and its potential for therapeutic exploitation. Cancer Res. 1989, 49, 4373-4384. [PubMed]

75. El-Kenawi, A.; Gatenbee, C.; Robertson-Tessi, M.; Bravo, R.; Dhillon, J.; Balagurunathan, Y.; Berglund, A.; Vishvakarma, N.; Ibrahim-Hashim, A.; Choi, J.; et al. Acidity promotes tumour progression by altering macrophage phenotype in prostate cancer. Br. J. Cancer 2019, 121, 556-566. [CrossRef]

76. Seddon, J.M.; Squires, A.M.; Conn, C.E.; Ces, O.; Heron, A.J.; Mulet, X.; Shearman, G.C.; Templer, R.H. Pressure-jump X-ray studies of liquid crystal transitions in lipids. Philos. Trans. Ser. A Math. Phys. Eng. Sci. 2006, 364, 2635-2655. [CrossRef] 